\title{
Impacts of the global sea surface temperature anomaly on the evolution of circulation and precipitation in East Asia on a quasi-quadrennial cycle
}

\author{
Senfeng Liu ${ }^{1,2} \cdot$ Anmin Duan ${ }^{1,2,3}$ (D)
}

Received: 30 October 2016 / Accepted: 24 March 2017 / Published online: 6 April 2017

(c) The Author(s) 2017. This article is an open access publication

\begin{abstract}
Based on multi-source observational data from 1979 to 2013, we investigate the evolution of the global sea surface temperature anomaly (SSTA) on a quasi-quadrennial cycle and its impact on the seasonal evolution of circulation and precipitation in East Asia. We do this by using principal oscillation pattern analysis and associated correlation pattern analysis, together with numerical experiments from an atmospheric general circulation model. The results indicate that the global SSTA exerts profound impacts on the East Asian climate anomaly, while distinct responses exist between the SSTA developing and decaying stages. From winter to autumn in the developing year, southern China is typically wetter than normal. In the decaying year, however, the precipitation over most parts of East Asia is above normal from winter to spring, and the main rainfall band meandering from the Yangtze River to
\end{abstract}

This paper is a contribution to the special issue on East Asian Climate under Global Warming: Understanding and Projection, consisting of papers from the East Asian Climate (EAC) community and the 13th EAC International Workshop in Beijing, China on 24-25 March 2016, and coordinated by Jianping Li, Huang-Hsiung Hsu, Wei-Chyung Wang, Kyung-Ja Ha, Tim Li, and Akio Kitoh.

Anmin Duan

amduan@lasg.iap.ac.cn

1 State Key Laboratory of Numerical Modeling for Atmospheric Sciences and Geophysical Fluid Dynamics, Institute of Atmospheric Physics, Chinese Academy of Sciences, Beijing 100029, China

2 College of Earth Science, University of Chinese Academy of Sciences, Beijing 100049, China

3 Collaborative Innovation Center on Forecast and Evaluation of Meteorological Disasters, Nanjing University of Information Science and Technology, Nanjing 210044, China
South Japan is enhanced in summer. During the developing and decaying years, an upper-level anomalous cyclone moves from Northeast Asia to the Tibetan Plateau, and then retreats back. A low-level anomalous cyclone occurs over Northeast Asia in spring, but weakens in summer and then strengthens gradually from autumn to the following summer. An anomalous Philippine Sea anticyclone occurs in winter and spring, but is replaced by an anomalous cyclone in summer before reappearing and persisting from autumn to the decaying year. The abrupt change in circulation patterns in summer of the developing year might be related to the anomalous weakening of the Tibetan Plateau heating. These anomalies can be attributed to the combined effects of the global large-scale heating, regional-scale oceanic forcing, and thermal feedback of the land.

Keywords East Asian climate $\cdot$ Global sea surface temperature anomaly · Principal oscillation pattern · Quasiquadrennial cycle $\cdot$ Numerical simulation

\section{Introduction}

The East Asian Monsoon (EAM) is a subsystem of the much larger Asian monsoon system, which is characterized by a prominent contrast between the winter monsoon and summer monsoon during its annual cycle (Ding and Chan 2005). Climatic anomalies of the EAM can bring flooding, drought and other meteorological disasters, which have substantial effects on the socioeconomic development of regions home to around two billion people in China, Korea and Japan. The interannual variability of the EAM has thus attracted considerable attention from scientific researchers over a period of many years; and yet despite these efforts, its level of predictability remains low (Song and Zhou 
2014a, b). Various external forcing factors modulate the interannual variability of the EAM via tropical, subtropical and mid-latitude circulation systems (Tao and Chen 1987; Zeng et al. 1994). Previous studies have documented that many sea surface temperature anomaly (SSTA) modes in the different ocean basins have considerable impacts on the interannual variability of the EAM, including the eastern and central Pacific El Niño types (Fu and Teng 1988; Wang et al. 2000; Yuan and Yang 2012), the Indian Ocean basin mode (IOBM) (Wu et al. 2000; Yang et al. 2007; He et al. 2015), and the Indian Ocean dipole (IOD) (Guan and Yamagata 2003; Yuan et al. 2008; Yang et al. 2010), as well as the SSTA in the western North Pacific ( $\mathrm{Lu}$ and $\mathrm{Lu} 2014$ ) or the tropical North Atlantic (Rong et al. 2010). Besides, land thermal forcing is also important, such as the thermal effects of snow cover on the Tibetan Plateau (Wu and Qian 2003; Xiao and Duan 2016), surface sensible heating (Luo and Chen 1995; Duan and Wu 2005), and condensation latent heating (Wang et al. 2014; $\mathrm{Hu}$ and Duan 2015), as well as Eurasian snow cover (Yang 1996; Wu and Kirtman 2007).

El Niño-Southern Oscillation (ENSO) is the most prominent air-sea interaction system with a global teleconnection effect, and it has substantial effects on the interannual variability of the EAM. The SSTA in the central and eastern Pacific has a close link with the SSTA variations in other ocean regions via an atmospheric "bridge" (Alexander et al. 2002, 2004). Prominent SSTA modes, including the eastern/central Pacific El Niño (NINO3/EMI) (Wang 2001; Ashok et al. 2007), the western North Pacific SSTA (WNP) (Lu and Lu 2014), the IOBM (Qu and Huang 2012), the IOD (Saji et al. 1999), and the tropical North Atlantic SSTA (TNA) (Rong et al. 2010), are often used to compare their relative influences upon regional climate anomalies. However, the Niño3 index has a significant lead-lag correlation with other SSTA indexes, revealing a periodic linkage in the evolution from a lead time of 2 years to a lag of 2 years (Fig. 1a). Figure 1b, c show that the East Asian winter and summer monsoon indices, defined by Wang and Chen (2014) and Wang et al. (2008b), have significant lead-lag correlations with the six prominent SSTA modes from a lead time of 2 years to a lag of 2 years, and these correlations occur in different time segments. The maximum and minimum of these correlation coefficients often span about 1-2 years, and display a prominent periodic feature. This suggests that the interannual variability of the EAM can to a great extent be attributed to the periodic oscillation of the global SSTA. Besides, ENSO has two dominant periods: the 3-5-year quasi-quadrennial cycle and the quasibiennial cycle (Jiang et al. 1995; Bejarano and Jin 2008). The anomalies of circulation and precipitation in East Asia also have analogous periodic variation features, and these are closely coupled with the quasi-quadrennial oscillation of the SSTA in the tropical Pacific (Chen et al. 1990; Zhu and Chen 2000; Zhu et al. 2004). The responses to ENSO are different between its developing and decaying stages (e.g., Huang and Wu 1989; Wang et al. 2000; Wang and Zhang 2002).

Previous studies based on observations or numerical simulations have mainly focused on the impacts of individual SSTA modes on the interannual variability of the EAM in a single ocean basin or a certain season. In fact, the global SSTA possesses an integral evolutionary feature with, to a certain degree, a prominent periodicity. Attempts to further our understanding of the SSTA effects on the interannual variability of the EAM should take account of SSTA evolution on a global spatial scale but with a temporal cyclic view. The present study aims to investigate the impacts of the global SSTA on the evolution of circulation and precipitation in East Asia on a quasi-quadrennial cycle. The hope is that the findings will contribute to an improved understanding of the mechanism involved, and enhance the predictability of the interannual variability of the EAM.

The remainder of the paper is structured as follows: Sect. 2 introduces the datasets, methods and the atmospheric general circulation model (AGCM) employed in the study. Section 3 presents the global SSTA quasi-quadrennial principal oscillation patterns and reveals their relationship with circulation and precipitation. Section 4 explores the different responses of circulation and precipitation in East Asia between the developing and decaying stages, based on both observational analysis and numerical simulations from the AGCM. Finally, Sect. 5 summarizes the study's key findings and provides some further discussion.

\section{Data, methods and model}

\subsection{Datasets}

The SST data are derived from the HadISST1 (Hadley Centre Sea Ice and Sea Surface Temperature) dataset, at a horizontal resolution of $1^{\circ} \times 1^{\circ}$ (Rayner et al. 2003). The European Centre for Medium-Range Weather Forecasts interim reanalysis (ERA-Interim), which consists of geopotential height, temperature, horizontal wind (zonal and meridional components), and vertical velocity in the isobaric coordinate system, and whose horizontal resolution is $1^{\circ} \times 1^{\circ}$, with 37 vertical pressure levels (Dee et al. 2011), is also employed. The precipitation data are from version 2.1 of the Global Precipitation Climatology Project (GPCP), at a horizontal resolution of $2.5^{\circ} \times 2.5^{\circ}$ (Adler et al. 2003). All the datasets comprise monthly means, and their temporal coverage is from 1979 to 2013. In order to focus on the interannual variability, the anomalies of the variables are 
(a) NINO3 \& SSTA indexes

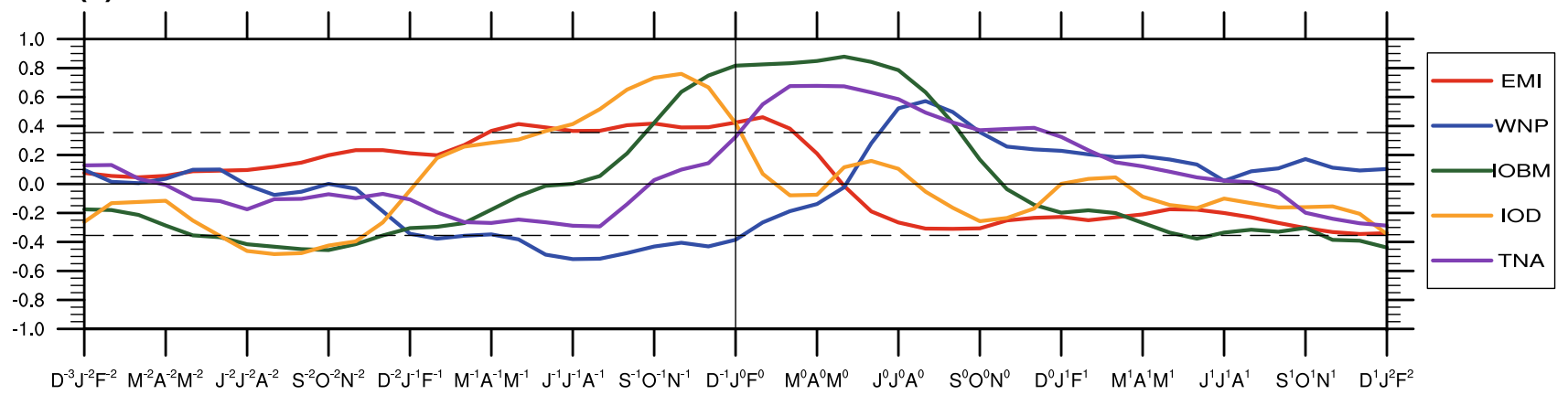

(b) EAWMI \& SSTA indexes

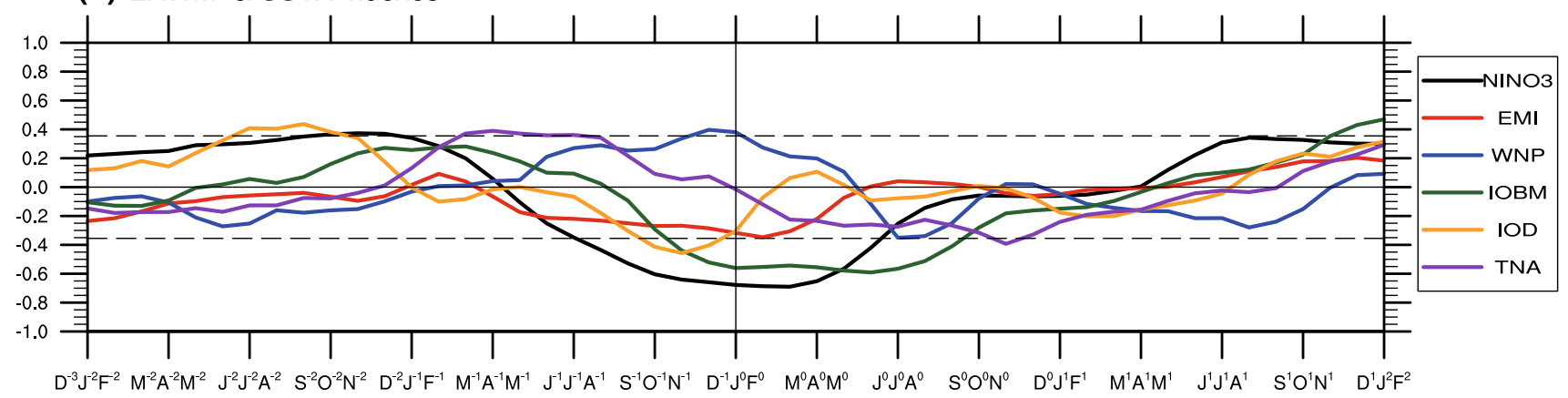

(c) EASMI \& SSTA Indexes

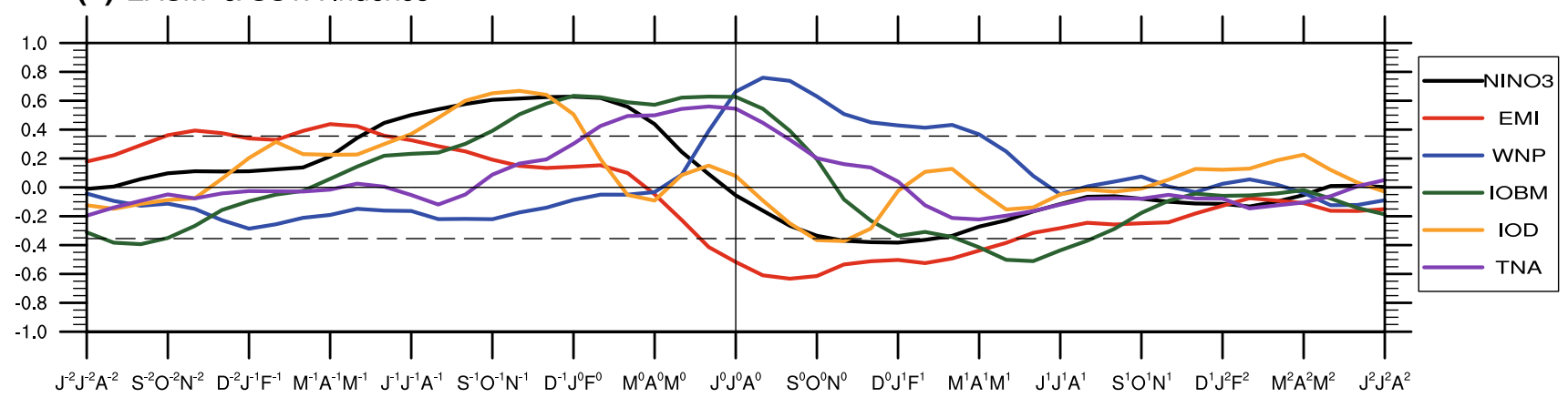

Fig. 1 Lead-lag correlations between a the Niño3 index [December-January-February mean; Wang (2001)] and the other five main SSTA indexes, b the East Asian winter monsoon index [December-January-February mean; Wang and Chen (2014)] and six main SSTA indexes, and $\mathbf{c}$ the East Asian summer monsoon index [JuneJuly-August mean; Wang et al. (2008b)] and six main SSTA indexes [NINO3 represents the eastern Pacific El Niño; EMI represents the

obtained by removing the climatological mean state and the long-term linear trend.

\subsection{Methods}

The main statistical methods used in the present study are "principal oscillation pattern (POP)" analysis and "associated correlation pattern (ACP)" analysis (Hasselmann 1988; Penland 1989; von Storch et al. 1995; Tang 1995). In the mathematics that follows, bold lowercase letters central Pacific El Niño or El Niño Modoki (Ashok et al. 2007); WNP represents the western North Pacific SSTA (Lu and Lu 2014); IOBM represents the Indian Ocean basin mode (Qu and Huang 2012); IOD represents the Indian Ocean Dipole (Saji et al. 1999); TNA represents the tropical North Atlantic SSTA (Rong et al. 2010); and the horizontal dashed lines denote the $95 \%$ confidence level]

indicate vectors, and bold uppercase letters are matrices. For a linear discretized real system,

$\mathbf{x}(t+1)=\mathbf{A} \cdot \mathbf{x}(t)+$ noise.

And using expectations $E$ can yield

$\mathbf{A}=E\left[\mathbf{x}(t+1) \mathbf{x}^{T}(t)\right] \cdot\left[E\left[\mathbf{x}(t) \mathbf{x}^{T}(t)\right]\right]^{-1}$.

A pair of conjugate eigenvectors of Eq. (2), $\boldsymbol{p}_{k}=\boldsymbol{p}_{k}^{r}+i \boldsymbol{p}_{k}^{i}$ and $\boldsymbol{p}_{k}^{*}=\boldsymbol{p}_{k}^{r}+i \boldsymbol{p}_{k}^{i}$, are called the principal oscillation patterns (POPs) or the normal modes of 
Eq. (1), where the superscript $r$ represents the real part and the superscript $i$ represents the imaginary part. So, the explained components or the reconstructed components of the $k$ th pair of POPs can be written as

$\hat{\mathbf{x}}_{k}(t)=z_{k}^{r}(t) \boldsymbol{p}_{k}^{r}+z_{k}^{i}(t) \boldsymbol{p}_{k}^{i}$,

where $z$ represents the POP time coefficients. The terms $z_{k}^{r}$ and $z_{k}^{i}$ can be obtained by solving a group of binary linear regression equations, whose number is equal to the length of time coefficients. The real part and imaginary part are two independent modes with similar timescale, so $z_{k}^{r}$ and $z_{k}^{i}$ are orthogonal in the time domain, and the phase of $z_{k}^{i}$ has $1 / 4$ periods in advance of the phase of $z_{k}^{r}$. The POPs can succeed in extracting the spatial and temporal propagation characteristics from a linear system. More details of POP analysis can be found in the review by von Storch et al. (1995).

As for ACP analysis, the associated linear correlation between another vector time series $\mathbf{y}(t)$ and the $k$ th pair of POPs derived from $\mathbf{x}(t)$ can be expressed as

$\tilde{\boldsymbol{y}}(t)=\tilde{z}_{k}^{r}(t) \boldsymbol{q}_{k}^{r}+\tilde{z}_{k}^{i}(t) \boldsymbol{q}_{k}^{i}+$ noise,

where $\boldsymbol{q}_{k}^{r}$ and $\boldsymbol{q}_{k}^{i}$ are called the associated correlation patterns (ACPs) of $\boldsymbol{y}(t)$ as the coupled response to the POPs of $\boldsymbol{x}(t)$, and an overhead tilde ( $\sim)$ denotes the normalization from $\boldsymbol{y}(t), z_{k}^{r}$ and $z_{k}^{i}$. We regard Eq. (4) as a suite of binary linear regression equations, whose number is equal to the number of dimensions of $\boldsymbol{y}(t)$, where $\tilde{\boldsymbol{y}}(t)$ is the response factor, and $\tilde{z}_{k}^{r}$ and $\tilde{z}_{k}^{i}$ are the predictors. So, the ACPs, $\boldsymbol{q}_{k}^{r}$ and $\boldsymbol{q}_{k}^{i}$, regarded as the regression coefficients, can be obtained by solving the linear regression equations.

The quasi-quadrennial POPs of the global SSTA are obtained using POP analysis. In order to highlight the interannual variability and remove the intraseasonal signal, the monthly data of the global SSTA $\left(60^{\circ} \mathrm{S}-60^{\circ} \mathrm{N}\right)$ are filtered using a low-pass nine-point Gaussian filter. As for the filtered SSTA field, the spatial degrees of freedom (Fraedrich et al. 1995) are 16.745. In the EOF (empirical orthogonal function) expansions, the cumulative explained variance of the first 16 principal components reaches $76.565 \%$, which is enough to express the SSTA interannual variability. To reduce the spatial degrees of freedom, only the first 16 principal components are selected and introduced into the POP analysis calculation. Table 1 shows the evaluation indicators of the eight pairs of POPs obtained. The first pair of POPs, with a period of 45.701 months, i.e., the quasiquadrennial scale, has the greatest explained variance percentage $(28.475 \%)$ and the greatest biasing factor (0.534). Figure 2 shows the quasi-quadrennial POPs and their time coefficients, including the real part and imaginary part. The power spectra for the time coefficients show that both the real part and the imaginary part peak at 48 months (Fig. 3). All these results indicate that the quasi-quadrennial POPs are the dominant evolutionary mode for the interannual variability of the global SSTA

The linkages between the climate anomalies over East Asia and the quasi-quadrennial POP of the global SSTA are attained by employing ACP analysis. Since the interannual variability of circulation and precipitation anomalies strongly depend on the seasonal climatology, the ACPs of the four seasons are calculated from the seasonal-mean time coefficients of the quasi-quadrennial POPs, respectively.

In a cycle, the evolution of the POPs is

$\cdots \rightarrow \boldsymbol{p}_{k}^{i} \rightarrow \boldsymbol{p}_{k}^{r} \rightarrow-\boldsymbol{p}_{k}^{i} \rightarrow-\boldsymbol{p}_{k}^{r} \rightarrow \boldsymbol{p}_{k}^{i} \rightarrow \cdots$,

and the corresponding evolution of the ACPs is

$\cdots \rightarrow \boldsymbol{q}_{k}^{i} \rightarrow \boldsymbol{q}_{k}^{r} \rightarrow-\boldsymbol{q}_{k}^{i} \rightarrow-\boldsymbol{q}_{k}^{r} \rightarrow \boldsymbol{q}_{k}^{i} \rightarrow \cdots$.

In fact, the quasi-quadrennial oscillations do not follow a strictly regular quadrennial period (Fig. 2c). In order to reconstruct the evolution of vector time series in a cycle, ideal time coefficients of trigonometric functions are designed artificially as

$z^{r}(t)=\sqrt{2} \sigma^{r} \sin (2 \pi t / T), z^{i}(t)=\sqrt{2} \sigma^{i} \cos (2 \pi t / T), t \in[0, T]$,

where $\sigma^{r}$ and $\sigma^{i}$ are the standard deviations estimated from observations, and $T$ is the oscillation period (Fig. 4). For an ideal quadrennial scale, we set $T=48$ in Eq. (7). Note that the correlation coefficient between the real time coefficient and the Niño3 index is 0.929 . The real part mainly reflects the ENSO cycle. The real time coefficient often peaks in December (Fig. 2c), with an obvious phase-lock feature, which is consistent with when the warm SSTA peaks at the end of the calendar year in an El Niño event (Rasmusson and Carpenter 1982). So, we let $t=0$ in Eq. (7) correspond to December in $\operatorname{Year}(0)$ and the real ideal time coefficient peak in December in Year(1). The ideal
Table 1 Evaluation indicators of the principal oscillation patterns

\begin{tabular}{|c|c|c|c|c|c|c|c|c|}
\hline No. & 1 & 2 & 3 & 4 & 5 & 6 & 7 & 8 \\
\hline Period (month) & 45.701 & 28.872 & 102.241 & 52.571 & 226.445 & 69.392 & 155.577 & 1648.545 \\
\hline $\begin{array}{l}\text { Explained vari- } \\
\text { ance percent- } \\
\text { age }\end{array}$ & 28.475 & 26.091 & 19.000 & 13.499 & 11.636 & 11.304 & 10.604 & 10.512 \\
\hline Biasing factor & 0.534 & 0.511 & 0.436 & 0.367 & 0.341 & 0.336 & 0.326 & 0.324 \\
\hline
\end{tabular}


(a) POP - Real spacial pattern

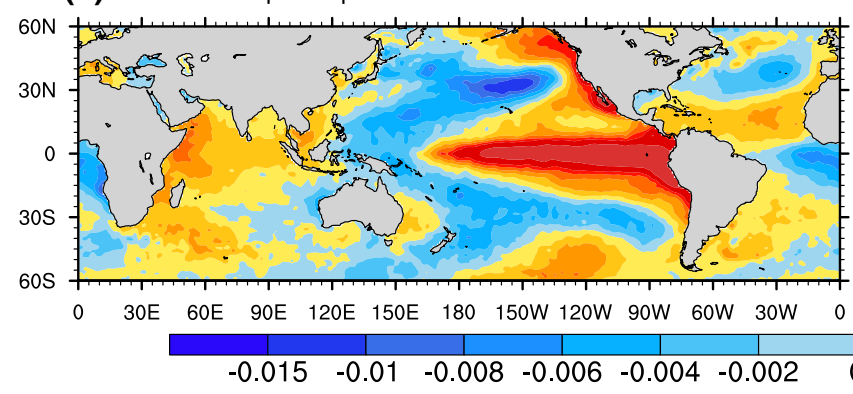

(c) POP - Time coefficient

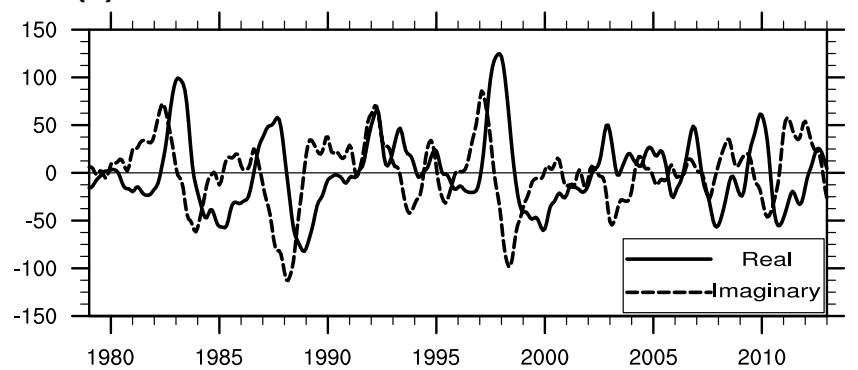

Fig. 2 Quasi-quadrennial POPs of the global SSTA: the a real part and $\mathbf{b}$ imaginary part of the spatial pattern; $\mathbf{c}$ the real and imaginary parts of the time coefficients; and $\mathbf{d}$ the explained variance ratio per-

quadrennial period is separated into four phases (Fig. 4). Every phase starts in December and ends in November of the following year, which consists of four seasons [winter-spring-summer-autumn, or DJF (December, January, February)-MAM (March, April, May)-JJA (June, July, August)-SON (September, October, November)]. According to the evolution of the real part of the ideal time coefficient, we define the four phases as the positive developing phase, the positive decaying phase, the negative developing phase, and the negative decaying phase, in turn. Replacing the time coefficients in Eqs. (3) and (4) with Eq. (7) enables us to obtain the ideal quadrennial evolution of the reconstructed components of the POPs and ACPs in a cycle.

As for the response patterns of circulation and precipitation derived from the reconstructed components of the ACPs and the results of the AGCM numerical simulations, in this study we focus on comparing the developing stage $[\operatorname{DJF}(0)-\mathrm{MAM}(0)-\mathrm{JJA}(0)-\mathrm{SON}(0)]$ and the decaying stage [DJF(1)-MAM(1)-JJA(1)-SON(1)]. They originate from the positive developing phase minus the negative developing phase, and the positive decaying phase minus the negative decaying phase, respectively.

\subsection{AGCM and experimental design}

The AGCM used in this study is the finite-volume atmospheric model (FAMIL), which is developed by the IAP/ (b) POP - Imaginary spacial pattern

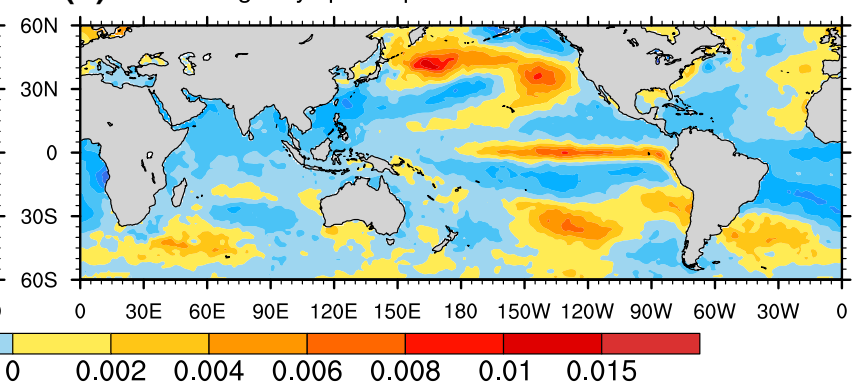

(d) POP _ Varaince ratio percent (\%)

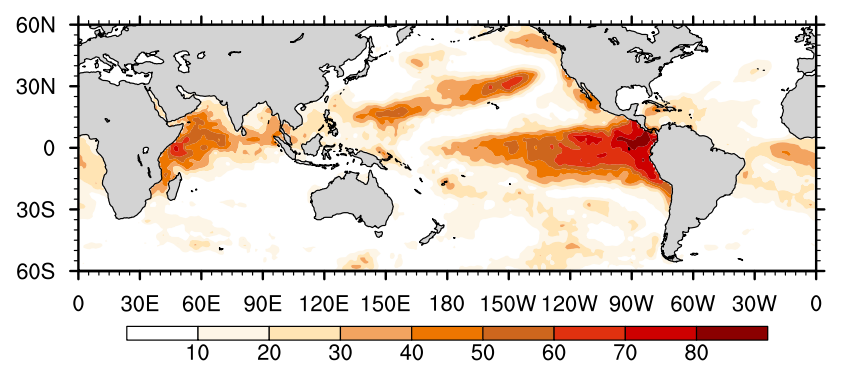

centage (units: \%, defined by the variance ratio between the reconstructed components and the integrated fields)

LASG (Institute of Atmospheric Physics/State Key Laboratory of Numerical Modeling for Atmospheric Sciences and Geophysical Fluid Dynamics) (Zhou et al. 2012, 2015; $\mathrm{Yu}$ et al. 2014). The FAMIL version with a finite-volume dynamical core is chosen in the present study. Also, we choose the horizontal resolution of $\mathrm{C} 48\left(1.875^{\circ} \times 1.875^{\circ}\right.$; about $200 \mathrm{~km}$ ) and 32 vertical levels, whose top level is $2.16 \mathrm{hPa}$. Its physical parameterizations are identical to those in the introduction provided by Hu and Duan (2015).

FAMIL has been widely employed in investigating the Asian monsoon and Tibetan Plateau meteorology (Liu et al. 2004; Wu et al. 2012; Duan et al. 2013; Hu and Duan 2015). It shows reasonable ability in simulating the Asian climate in terms of the annual periodic climatology and interannual variability. In the FAMIL control experiment, the seasonal evolutions in an annual cycle of the low-level circulation and precipitation, in terms of the climatological mean state, display an overall close similarity with observations (Fig. 5). Also, FAMIL can reproduce the dominant systems of the Asian winter and summer monsoons well. However, in terms of model bias, in the four seasons, the low-level velocity is overestimated over the tropical Indian Ocean and Northeast Asia, and the precipitation is overestimated over the tropical Indian Ocean and the Tibetan Plateau. Compared with observations, the main rainfall band over East Asia shifts northwards slightly in simulations from spring to summer, while it is underestimated in fall. 
(a) Power spectrum - Real time coefficient

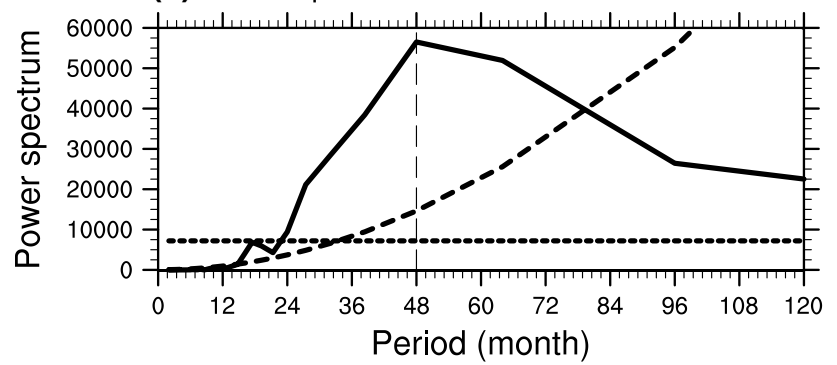

(b) Power Spectrum - Imaginary time coefficient

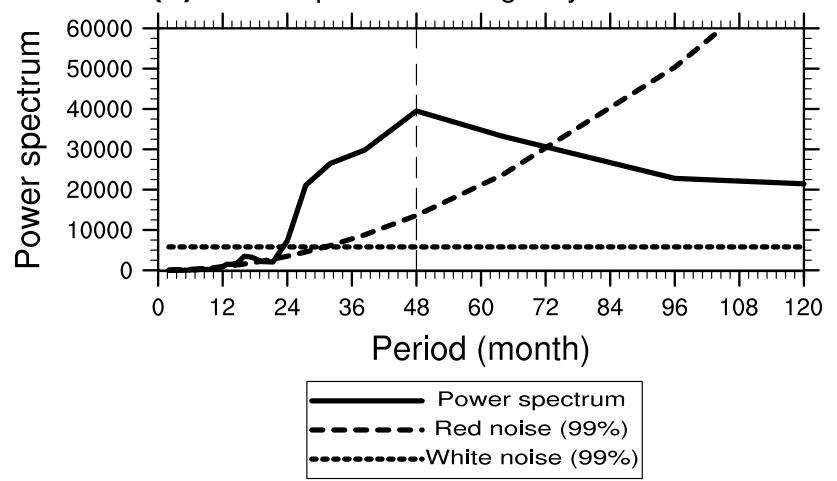

Fig. 3 Power spectra for the time coefficients of the quasi-quadrennial POPs using the Blackman-Tukey method: a real part; b imaginary part (the long dashed lines indicate the $99 \%$ confidence level in the red noise significant test, and the short dashed lines indicate the 99\% confidence level in the white noise significant test)

(a) Ideal time coefficient

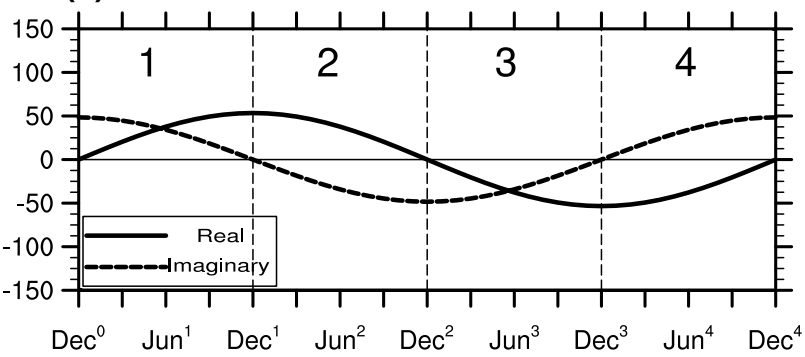

Fig. 4 Ideal time coefficients with a quadrennial period, in which the solid curve denotes the real part and the dashed curve denotes the imaginary part, and four separate phases are indicated by the vertical dashed lines

To verify the impacts of the global SSTA quasi-quadrennial POPs on the circulation and precipitation anomalies over East Asia, three groups of AGCM numerical experiments are designed and performed (Table 2). The AMIP2 experiment (AMIP: Atmospheric Model Intercomparison Project) is performed to estimate the standard variances of the circulation and precipitation in simulation results when forced by the SSTA on natural variability. The control experiment (CTL) is performed for the evaluation of the model as mentioned above. The sensitivity experiments (POP) are forced by the global SSTA $\left(60^{\circ} \mathrm{S}-60^{\circ} \mathrm{N}\right)$ reconstructed from the ideal quadrennial POPs as shown in Fig. 6, but with monthly evolution, and whose time integration length is 80 years (containing 20 cycles). The amplitude of oscillation is enlarged to two times the standard deviation of natural interannual variability. A 25-point spatial running average is employed along $60^{\circ} \mathrm{S}$ and $60^{\circ} \mathrm{N}$ to smooth the discontinuous gradient.

\section{The global SSTA quasi-quadrennial POPs}

\subsection{Spatial and temporal features}

The real part of the global SSTA quasi-quadrennial POPs shows an El Niño-like pattern (Fig. 2a). A warm SSTA is found in the tropical central-eastern Pacific, the eastern North Pacific, and the tropical North Atlantic, and expands from the Indian Ocean to the South China Sea. A cold SSTA extends from central South Pacific via the tropical western Pacific to the central Pacific. For the imaginary part, the Indian Ocean, the western Pacific, and the Atlantic, mainly display a cold SSTA (Fig. 2b). The areas exceeding $40 \%$ in the variance ratio percentage pattern are consistent with the high value centers in the real part. So, the real part contributes the most variance to the quasiquadrennial POPs.

Figure 6 shows the seasonal evolution of the global SSTA reconstructed from the ideal quadrennial POPs. In the positive developing phase, a warm SSTA in the tropical central and eastern Pacific is developing gradually from winter to autumn, and peaks in the following winter. It shows a delayed-type El Niño in the positive decaying phase, which remains a warm SSTA to summer (Ren et al. 2016). In the positive developing phase, the SSTA in the tropical Indian Ocean starts as a cold IOBM in winter, and then develops to an IOD during spring to summer, which peaks in autumn before disappearing rapidly. In the positive decaying phase, a warm IOBM persists from winter to autumn. The North Atlantic mainly features a positive-negative-positive tripole pattern in the positive developing and decaying phase. The seasonal evolution in the negative phase is in accordance with the positive phase, but with an opposite sign.

\subsection{Different role of the real and imaginary parts}

The ACPs of circulation and precipitation in the four seasons (winter-spring-summer-autumn, or DJF-MAM-JJA-SON) display distinct characteristics, which are attributable to the phase locking of the SSTA 
(a) OBS

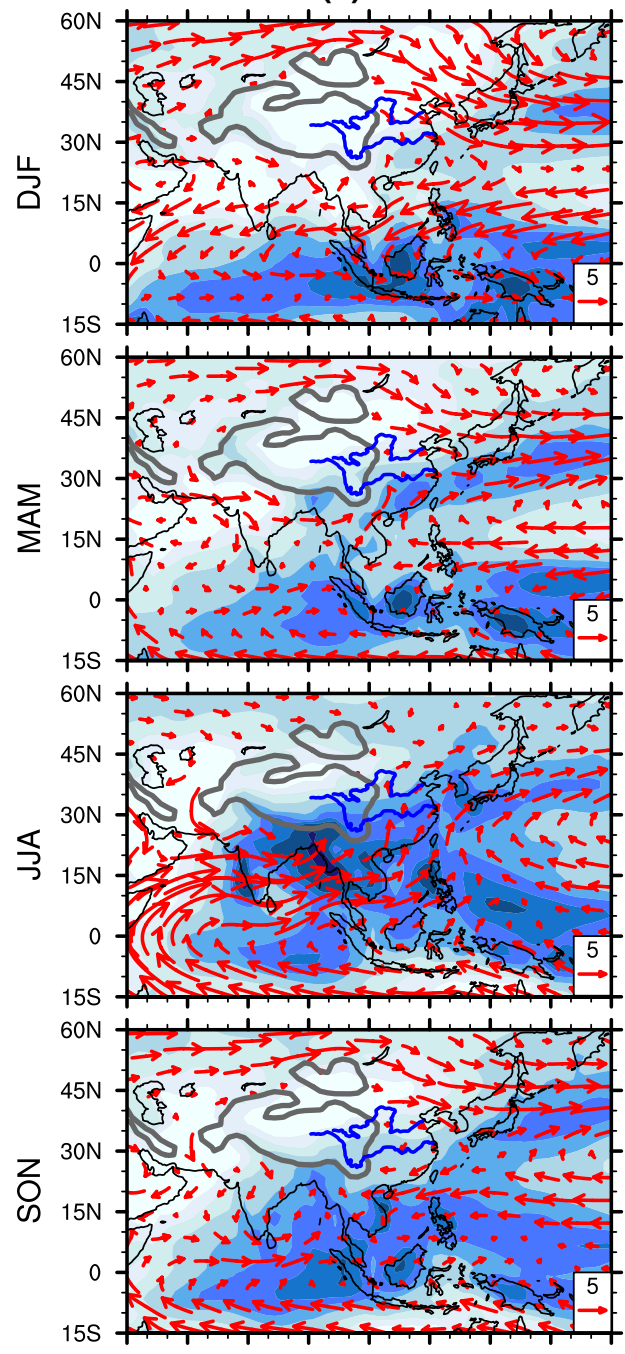

(b) FAMIL

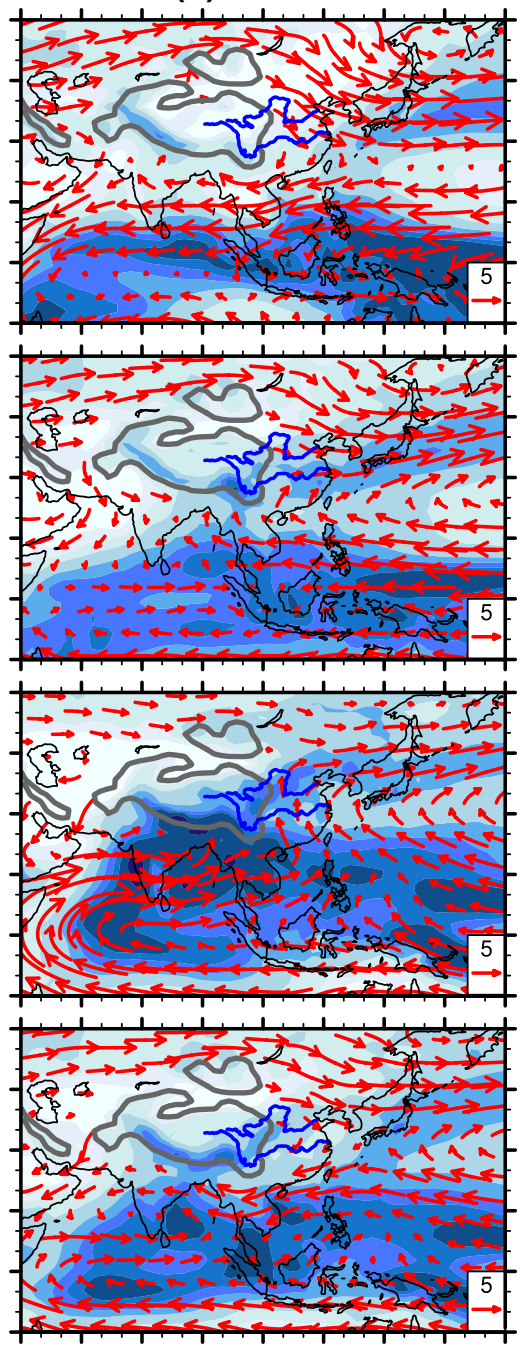

(c) FAMIL minus OBS
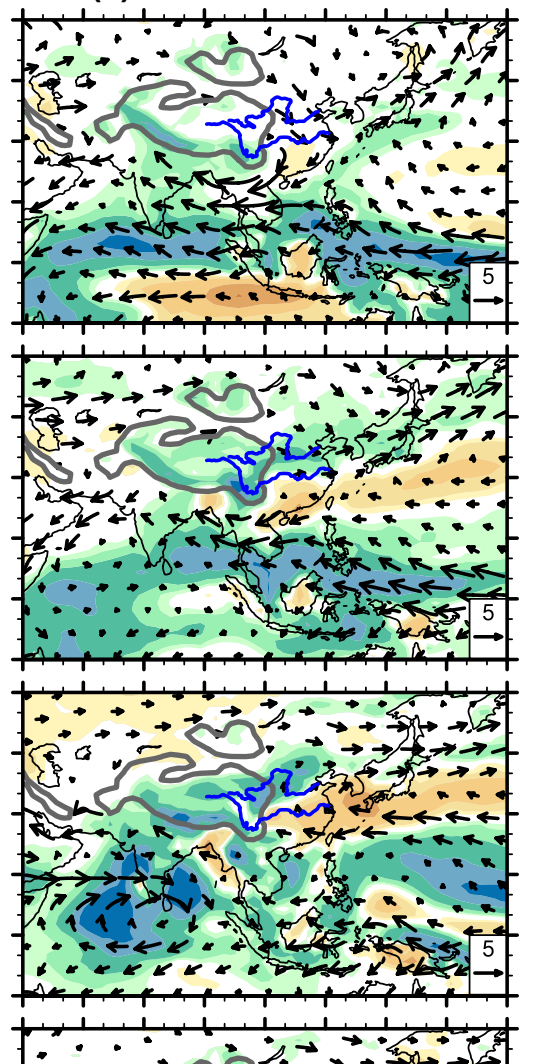

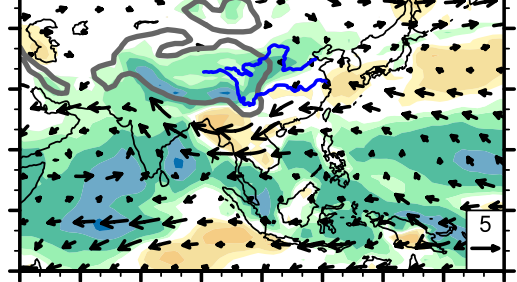

45E 60E 75E 90E 105E 120E 135E 150E 165E 45E 60E 75E 90E 105E 120E 135E 150E 165E 45E 60E 75E 90E 105E 120E 135E 150E 165E

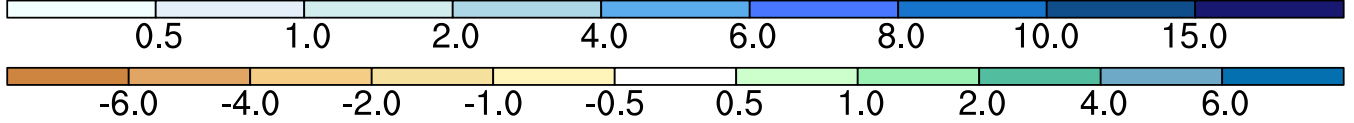

Fig. 5 Seasonal evolution of the climate mean 850 -hPa horizontal wind velocity and precipitation, in a observation (left panels), b the control run of FAMIL (middle panels), and $\mathbf{c}$ their difference fields (right panels) [the units for wind speed and precipitation are $\mathrm{m} \mathrm{s}^{-1}$ and $\mathrm{mm}$ day $^{-1}$, respectively; the gray bold curves represent altitude above $1500 \mathrm{~m}$; the blue bold lines over East Asia represent the Yangtze River and Yellow River from south to north (the same in subsequent figures)]
Table 2 Design of the AGCM numerical simulation experiments

\begin{tabular}{lll}
\hline Experiment & Design & $\begin{array}{l}\text { Integra- } \\
\text { tion length } \\
\text { (years) }\end{array}$ \\
\hline AMIP2 & Global SST/sea ice prescribed by AMIP2 from 1979 to 2009 & 31 \\
CTL & Annual periodic climatological monthly SST/sea ice & 30 \\
POP & Addition of the ideal quadrennial POPs of the global SSTA & 80 \\
\hline
\end{tabular}



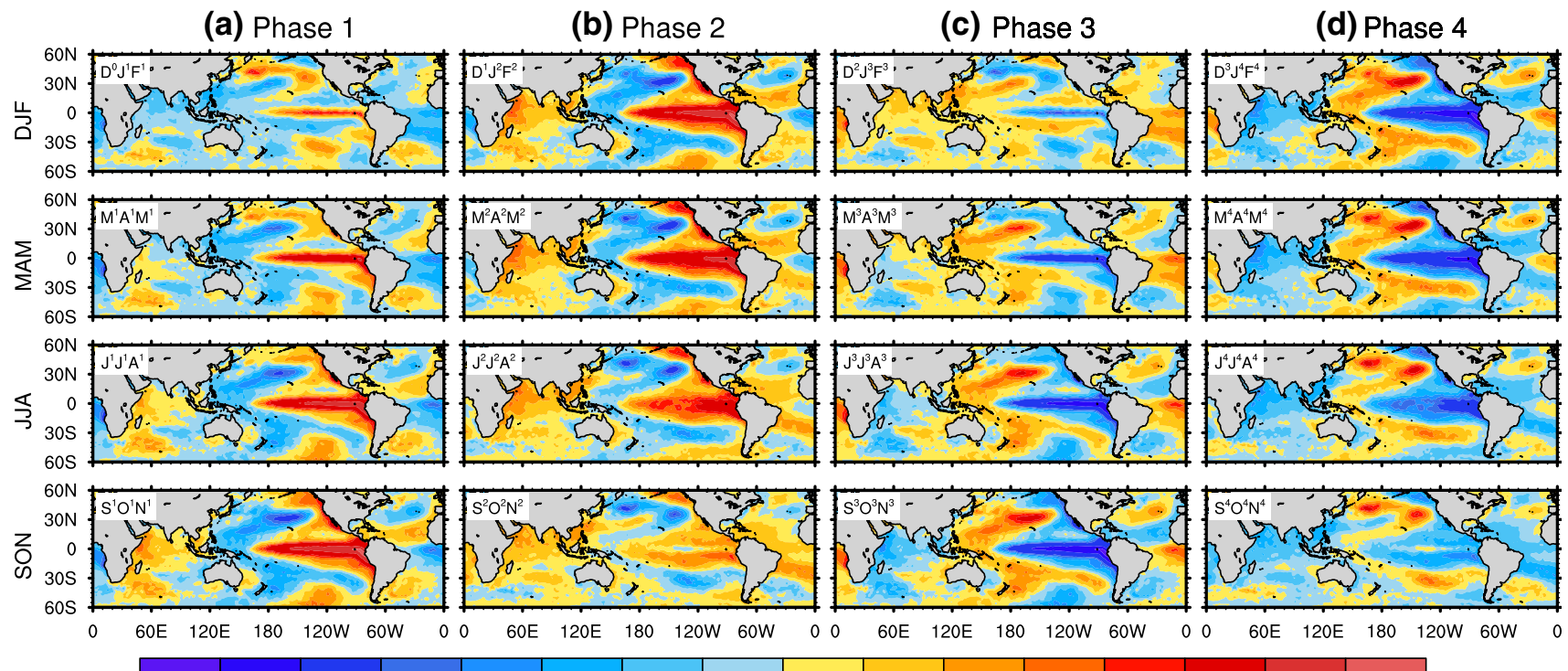

$-1.5 \quad-1.0 \quad-0.5 \quad-0.4$
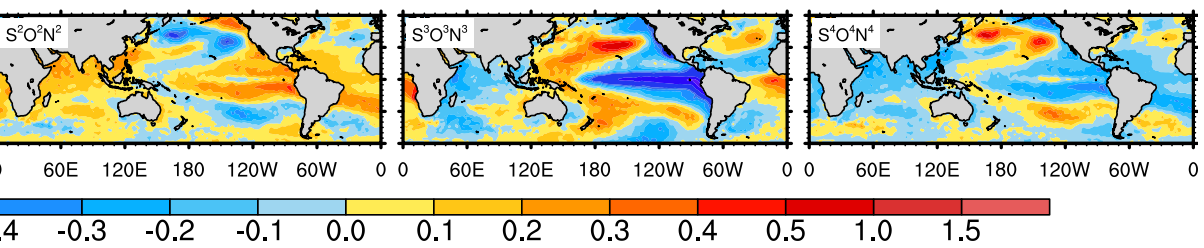

$0.5 \quad 1.0 \quad 1.5$

Fig. 6 Seasonal evolution of the global SSTA reconstructed from the ideal quadrennial POPs

evolution and the distinct climatological mean states of the four seasons. The relationship derived from the real part of the global SSTA quasi-quadrennial POPs (Fig. 7) is stronger than that from the imaginary part (Fig. 8). They reveal that the global SSTA quasi-quadrennial POPs have significant relationships with the global-scale anomalies of circulation and precipitation.

For the real part of the ACPs (Fig. 7), all year round, the mainly warm SSTAs in the tropics lead to the significant positive anomalous geopotential height at $200 \mathrm{hPa}$, due to global large-scale heating. Anomalous westerlies prevail over the boreal subtropics, resulting from the quasi-geostrophic equilibrium with the anomalous geopotential height gradient. Typical Matsuno-Gill (Matsuno 1966; Gill 1980) pattern responses can be found over the tropical Pacific and Indian Ocean, where anomalous anticyclones on both sides of the equator are the Rossby wave response to anomalous heating in the tropics. Over the tropical central Pacific, the anomalous lower-level convergent westerly and the anomalous upper-level divergent easterly associated with the positive anomalous precipitation construct the ascending branch of Walker circulation. Over the Maritime Continent, the convergence induced by the northwesterly and the southwesterly in the upper troposphere results in the subsidence branch of Walker circulation and the weakening of precipitation. At $200 \mathrm{hPa}$, the Pacific-North America (PNA) teleconnection pattern is characterized by the anomalous positive-negative-positive geopotential height, as well as the anomalous anticyclone-cyclone-anticyclone circulation from the Pacific to North America (Trenberth et al. 1998; Alexander et al. 2002). The PNA pattern is particularly prominent in winter, relatively weak in spring and autumn, and negligible in summer. Note that the ACPs in East Asia vary from winter to autumn. For the upper-level circulation, in winter, the dipole pattern with the anomalous negative-positive geopotential height is associated with anomalous cyclone-anticyclone circulation from south to north. In spring, a southwestern-northeastern slanted positive-negative-positive-negative wave-like pattern expands from the Indian Ocean to Northeast Asia, accompanied by an anomalous cyclone over the southern part of China and an anomalous anticyclone over Northeast Asia. This pattern is similar to that found when forced by the warm spring IOBM (Liu and Duan 2017). In summer, the tropics and mid-latitudes show a positive-negative seesaw pattern of anomalous geopotential height, which enhances the South Asian high and the westerly East Asian jet. In autumn, the tropics, subtropics and mid-latitudes show a positive-negative-positive pattern from south to north. In the lower troposphere, the western North Pacific anomalous anticyclone persists from winter to autumn, in association with the enhanced and western-expanded western North Pacific subtropical high, which induces the anomalous southwesterly wind and the positive anomalous precipitation from South China to South Japan.

For the imaginary part (Fig. 8), the overall relationship is weaker than that of the real part. Note that in summer, the anomalous cyclone associated with the enhanced precipitation is found over the Philippine Sea. Concurrently, the weakened southwesterly over southern China leads to the suppressed main rainfall band from the Yangtze River to southern Japan, which is in accordance with the negative phase of the leading mode of the East Asian summer monsoon (Wang et al. 2008b). 
(a) H20O \& UV20O
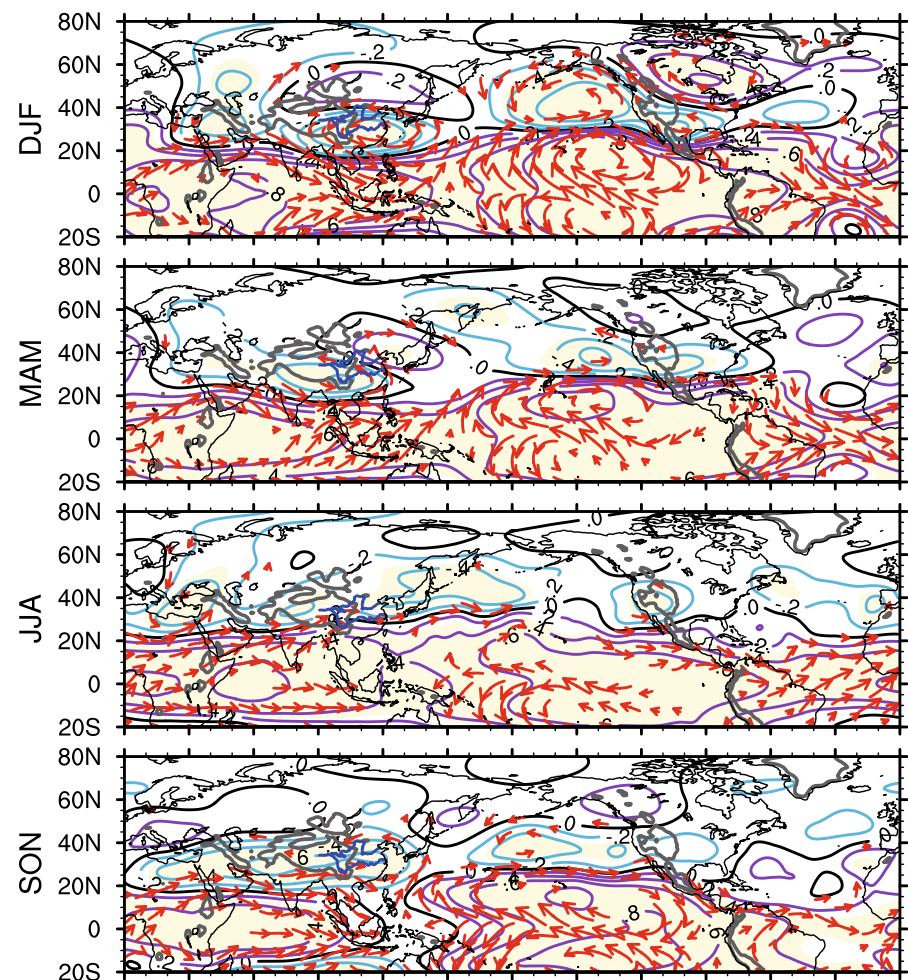

$0 \quad 30 \mathrm{E}$ 60E 90E 120E 150E 180 150W120W 90W 60W 30W (b) $\operatorname{Pr} \&$ UV850

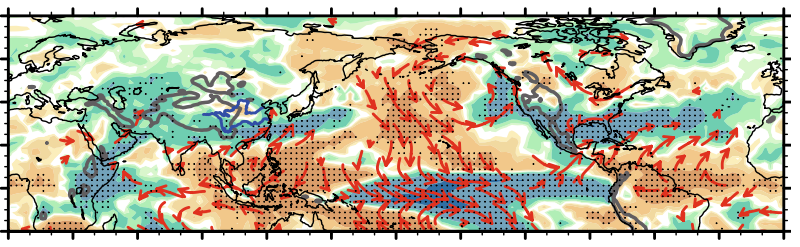

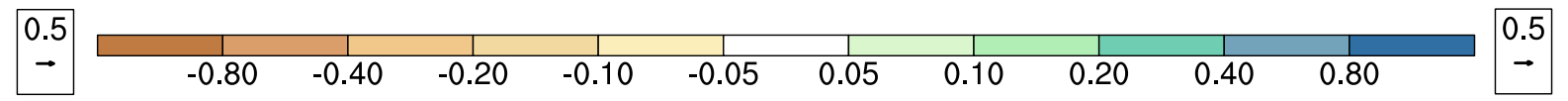

Fig. 7 The real part of the ACPs of a 200-hPa geopotential height and 200-hPa horizontal velocity (left panels) and $\mathbf{b}$ precipitation and 850-hPa horizontal velocity (right panels) [in a the 200-hPa geopotential height is depicted by contours with an interval of 0.2 (black contours are zero; purple contours are positive; blue contours are negative; yellow shading denotes the $95 \%$ confidence level), and the
200-hPa horizontal velocity is depicted by vectors (red vectors denote the $95 \%$ confidence level); and in $\mathbf{b}$ the precipitation is depicted by shading (black dots denote the $95 \%$ confidence level) and the $850-\mathrm{hPa}$ horizontal velocity is depicted by vectors (red vectors denote the $95 \%$ confidence level)]

is related to the high-low zonal gradient from the western Indian Ocean to the Maritime Continent. In the decaying stage, the warm IOBM and El Niño induce the anomalous high at $200 \mathrm{hPa}$.

The precipitation anomalies associated with the convection heating in the tropical Indian Ocean-western Pacific can affect the circulation through tropical atmospheric waves, i.e., Rossby waves and Kelvin waves. In $\operatorname{DJF}(0)$ and $\operatorname{MAM}(0)$, the suppressed precipitation from the tropical Indian Ocean to the Maritime Continent can induce the descending Rossby wave response, displaying two lowlevel anticyclones over the North Indian Ocean and the Philippine Sea, where the upper level shows an anomalous cyclone. In JJA(1), the suppressed precipitation from the North Indian Ocean to the Maritime Continent is associated with an elongated anticyclonic ridge. From $\mathrm{SON}(0)$ to MAM(1), the suppressed precipitation and low-level anticyclone appear from the Arabian Sea via the Bay of Bengal low. The development of the IOD from $\mathrm{JJA}(0)$ to $\mathrm{SON}(0)$ 
(a) H200 \& UV200
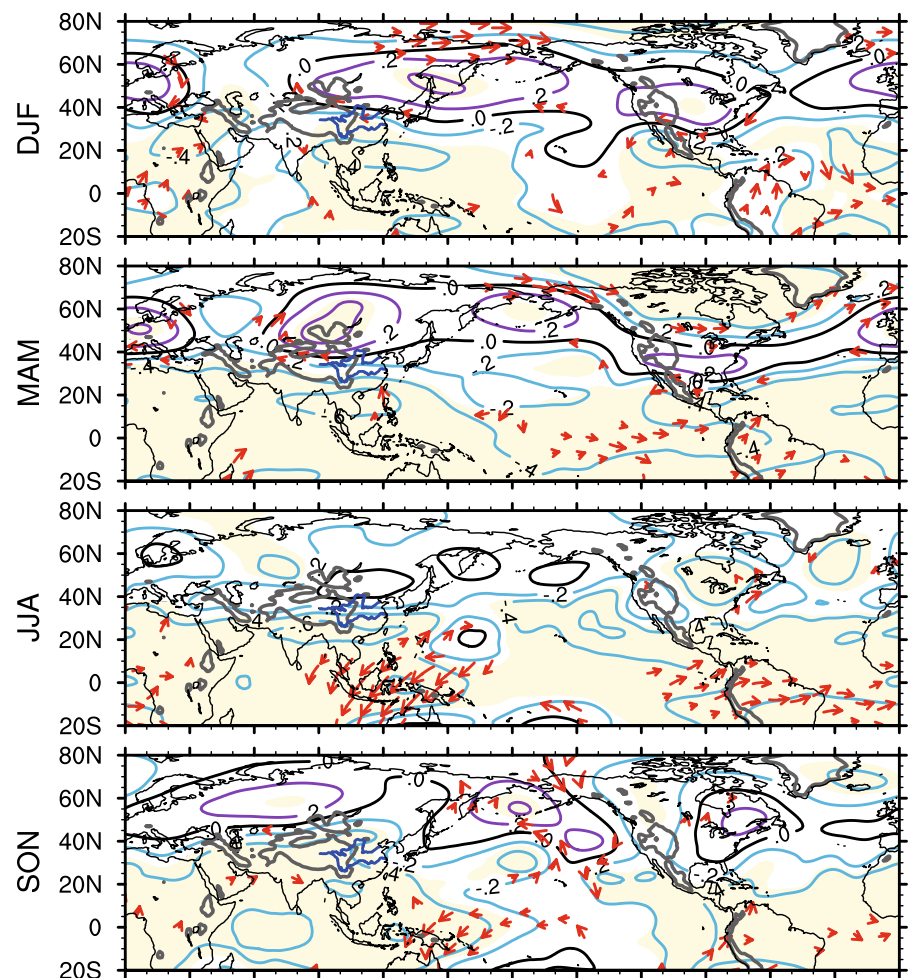

(b) $\operatorname{Pr} \&$ UV850
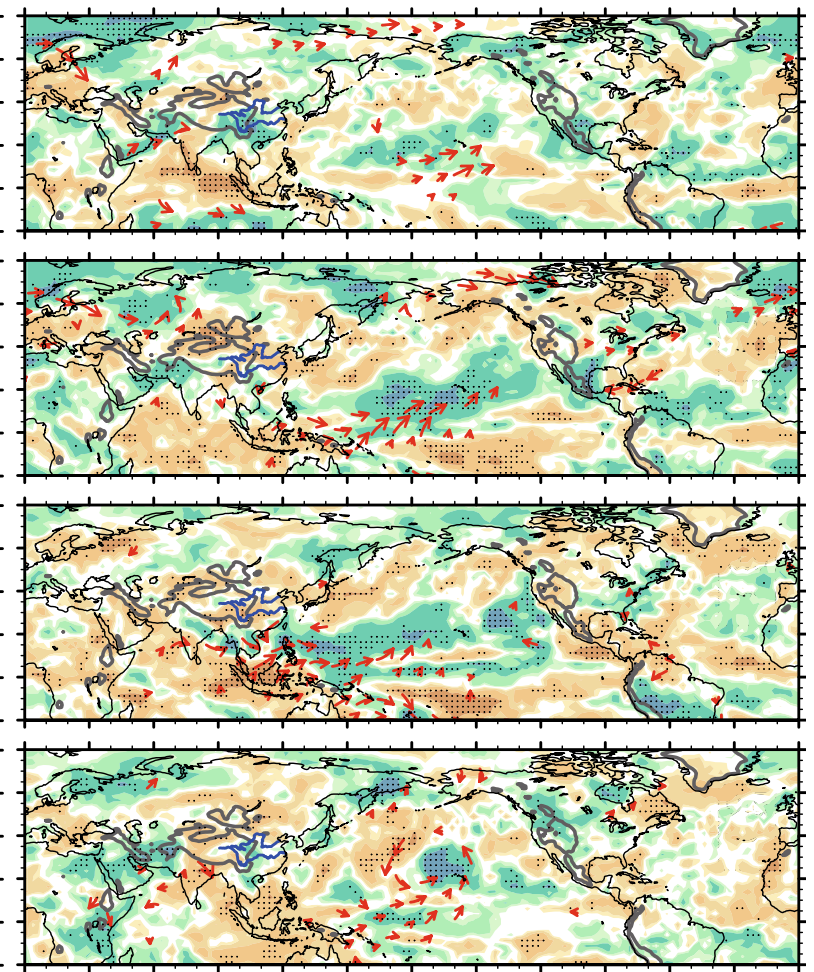

$030 \mathrm{E}$ 60E 90E 120E 150E 180 150W120W 90W 60W 30W 00 30E 60E 90E 120E 150E 180 150W120W 90W 60W 30W 0

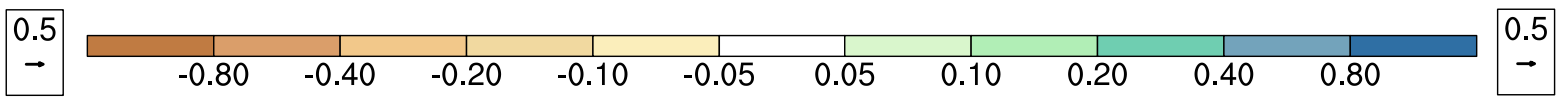

Fig. 8 As in Fig. 7 but for the imaginary part

to the Philippine Sea. Meanwhile, the rainfall in the southwestern Indian Ocean increases gradually. In JJA(1), the precipitation in the Indian Ocean is enhanced in association with an anomalous low-level cyclone, while that in the Philippine Sea is suppressed alongside an anomalous lowlevel anticyclone. In the developing and decaying years, anomalous northwesterly and southwesterly flow prevail in the upper troposphere of the tropical Indian Ocean-western Pacific, whose convergences constitute the downward branch of Walker circulation and shift from the Indian Ocean via the Maritime Continent to the western Pacific.

In East Asia, from $\operatorname{DJF}(0)$ to $\mathrm{SON}(0)$, southern China gets wetter but other regions get dryer. From $\operatorname{DJF}(1)$ to MAM(1), the precipitation in most regions of East Asia is above normal. In JJA(1), the main rainfall band meandering from the Yangtze River to South Japan is enhanced obviously. For the anomalous low-level circulations, the anomalous Philippine Sea anticyclone appears in $\operatorname{DFJ}(0)$ and $\operatorname{MAM}(0)$, but is replaced by an anomalous cyclone in $\mathrm{JJA}(0)$, then reappears in $\mathrm{SON}(0)$, and persists in the decaying year. Besides, an anomalous cyclone occurs in Northeast Asia in MAM(0) but weakens in JJA(0). Subsequently, it develops over the Yangtze River-Yellow River from $\operatorname{SON}(0)$ to $\operatorname{MAM}(1)$, and peaks in Northeast Asia in JJA(1). In the upper troposphere, in SON(0), an anomalous low, together with an anomalous cyclone, expands from the Iranian Plateau via the Tibetan Plateau to the East China Sea. In DJF(1), an almost meridional symmetrical dipole of anomalous low-high pressure, with a cyclonic-anticyclonic anomaly, controls East Asia. In MAM(1), this anomalous low-high pattern slants from southwest to northeast. In JJA(1), enhanced westerly flow prevails over the subtropics and the geopotential height anomaly shows a positive-negative seesaw pattern between the tropics and the mid-latitudes.

\subsection{Response in numerical simulations}

Figures 11 and 12 show the results of the AGCM numerical simulation forced by the ideal quadrennial POPs of the global SSTA in the developing and decaying stages, respectively. The results from the numerical simulations verify that the global SSTA has a significant impact on the circulation and precipitation anomalies. The responses show 
(a) H200 \& UV200
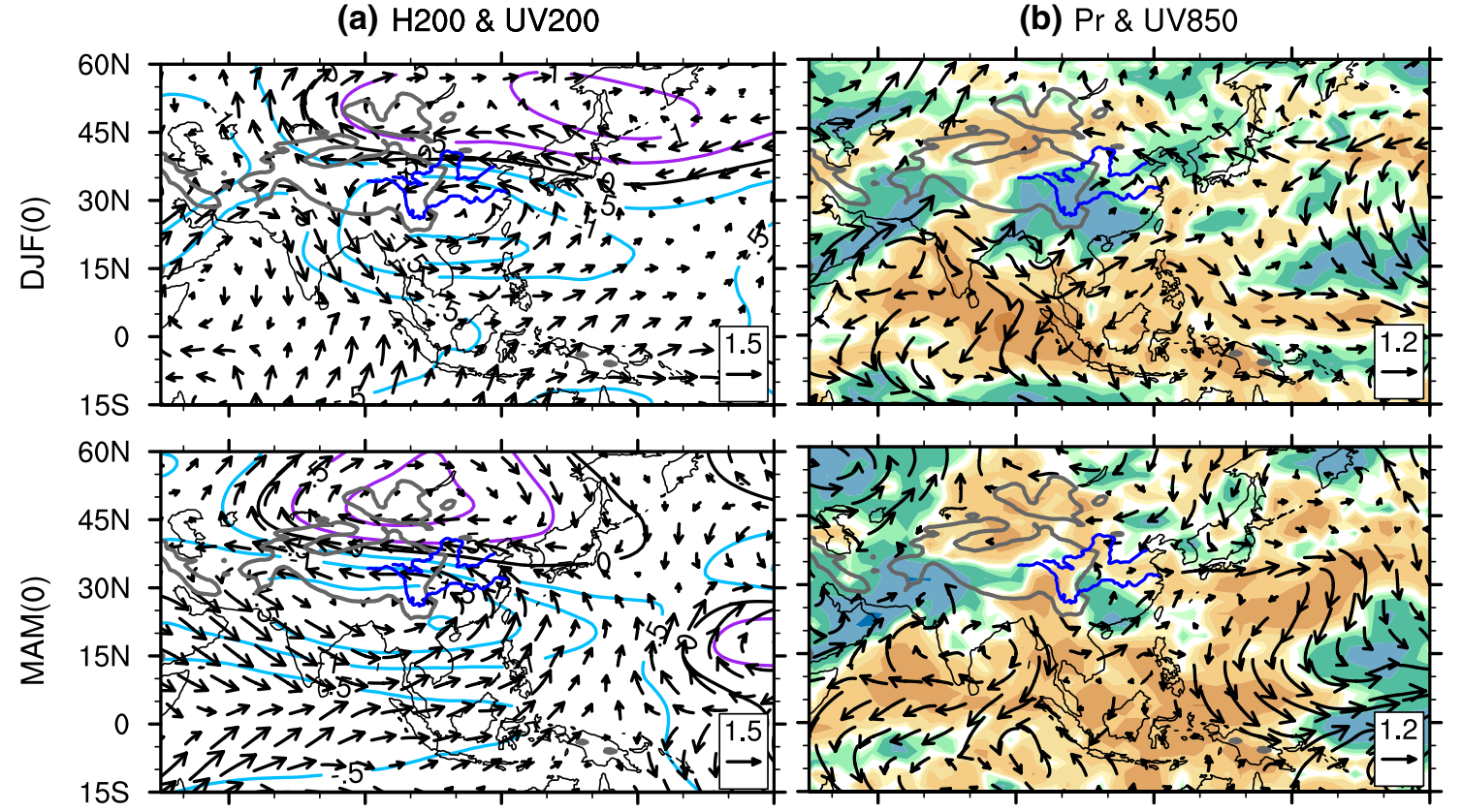

(b) $\operatorname{Pr} \&$ UV850
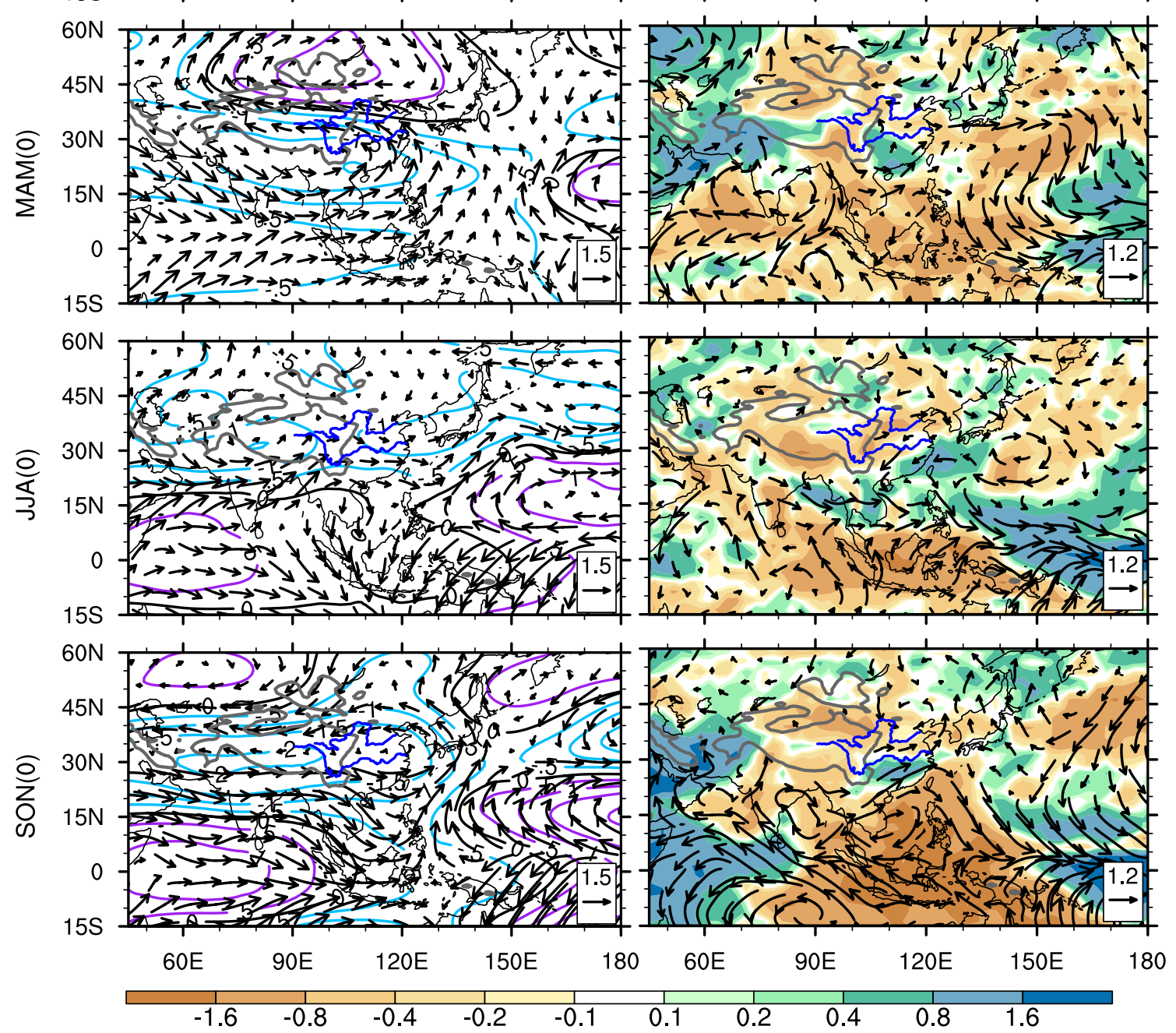

Fig. 9 Seasonal evolution in the developing stage of the reconstructed components of the ACPs derived from observations, in which results originate from the normalized differences between the positive and negative phases in a quadrennial cycle: a $200-\mathrm{hPa}$ geo-

overall similarity with the reconstructed components of the ACPs, albeit with some differences, such as the southward shift of the upper-level circulation patterns in East Asia in $\operatorname{DJF}(0)$, and their westward shift in $\operatorname{MAM}(0)$.

The anomalous Philippine Sea anticyclone is a crucial system for connecting the SSTAs in the tropics to the potential height [contours, with an interval of 0.5 (black contours are zero; purple contours are positive; blue contours are negative)] and 200-hPa horizontal wind (vectors); b precipitation (shading) and 850$\mathrm{hPa}$ horizontal wind (vectors)
East Asian monsoon (Huang and Wu 1989; Chang et al. 2000; Wang et al. 2000; Xie et al. 2016). From DJF(0) to $\operatorname{MAM}(0)$, the cold SSTAs with suppressed precipitation over the western Pacific stimulate Rossby wave responses with low-level anomalous anticyclones and upper-level anomalous cyclones over the Philippine Sea. In JJA(0), 
(a) H20O \& UV200
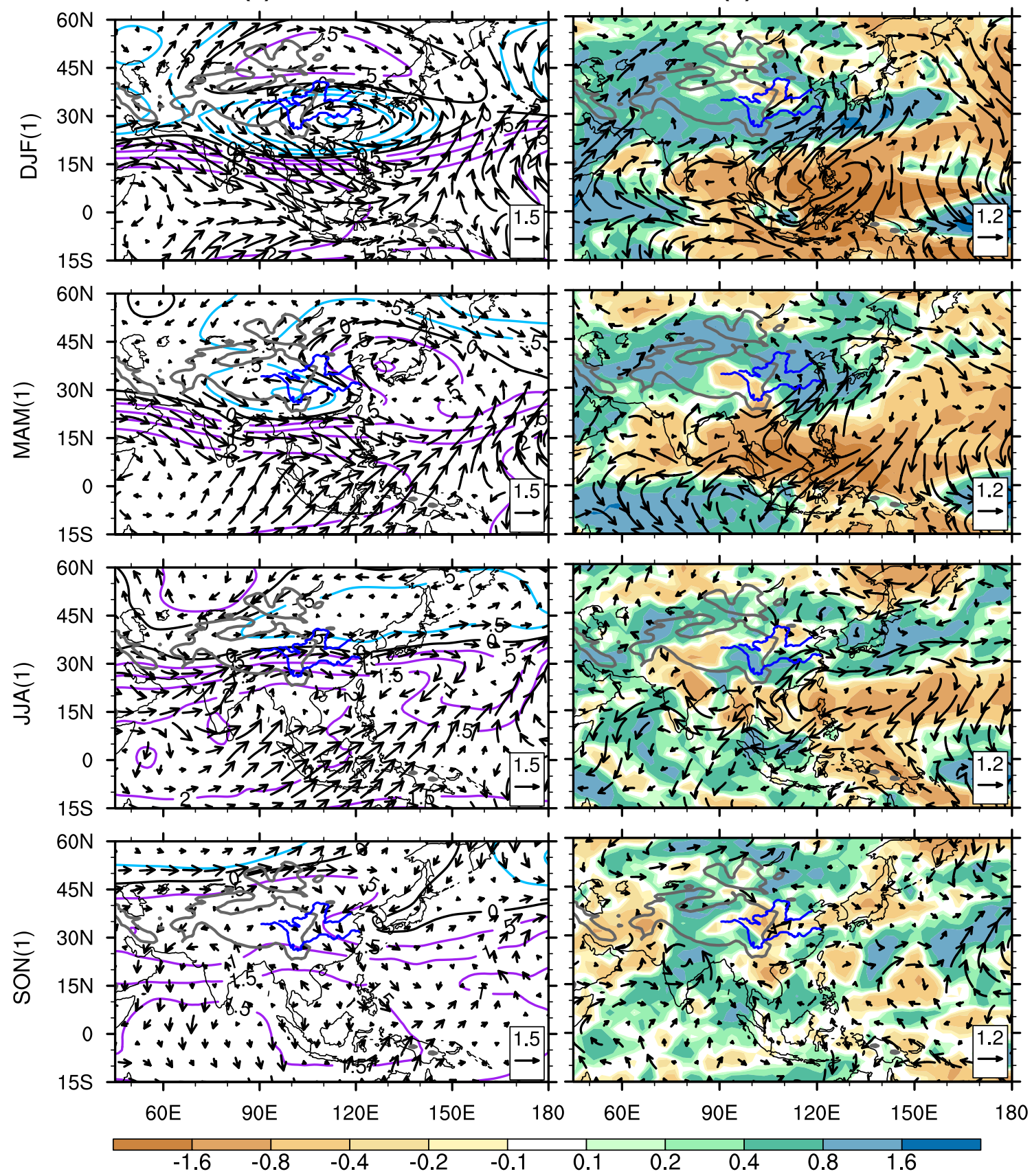

(b) $\operatorname{Pr} \&$ UV850
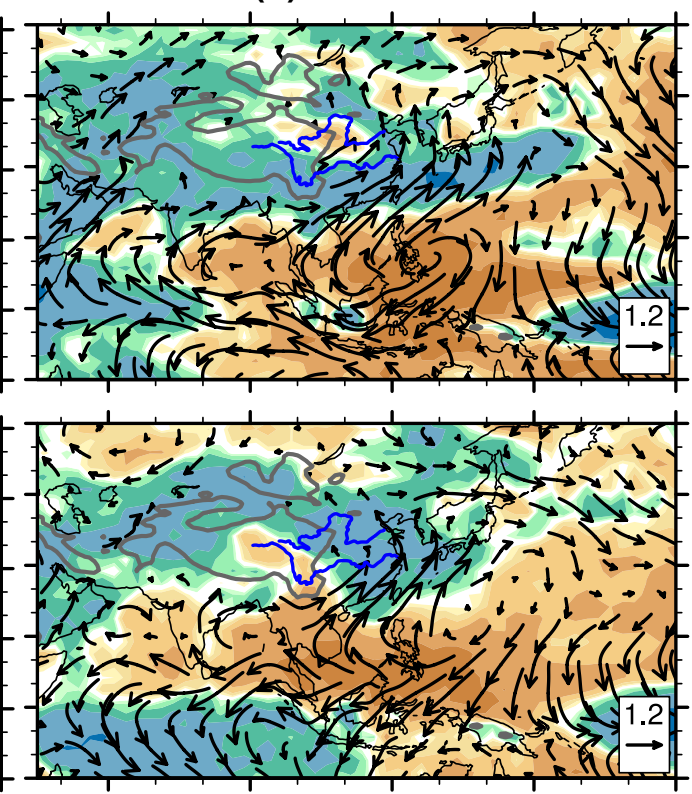

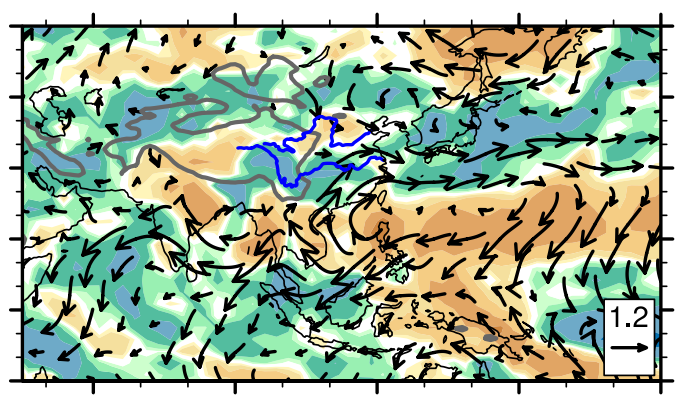

Fig. 10 As in Fig. 9 but for the decaying stage

however, the lower troposphere over the Philippine Sea displays an anomalous low-level cyclone rather than an anticyclone. The reduced atmospheric diabatic heating associated with suppressed precipitation over the tropical Indian Ocean contributes to its formation via eastwardpropagating cold Kelvin waves (Xie et al. 2009). El Niño induces the anomalous westerly as part of the Walker circulation over the tropical western and central Pacific (Wang and Zhang 2002). Both contribute a strong positive shear vorticity over the Maritime Continent, which enhances the cyclonic anomaly and thus the precipitation over the Philippine Sea. In addition, the reduced Tibetan Plateau heating related to suppressed precipitation in $\mathrm{JJA}(0)$ might to a certain degree be responsible for the development of the anomalous Philippine Sea cyclone, via a Rossby wave train propagating along the South Indian Monsoon westerly (Wang et al. 2008a, 2014; Hu and Duan 2015). In SON(0), the anomalous Philippine Sea anticyclone establishes 
(a) H200 \& UV200
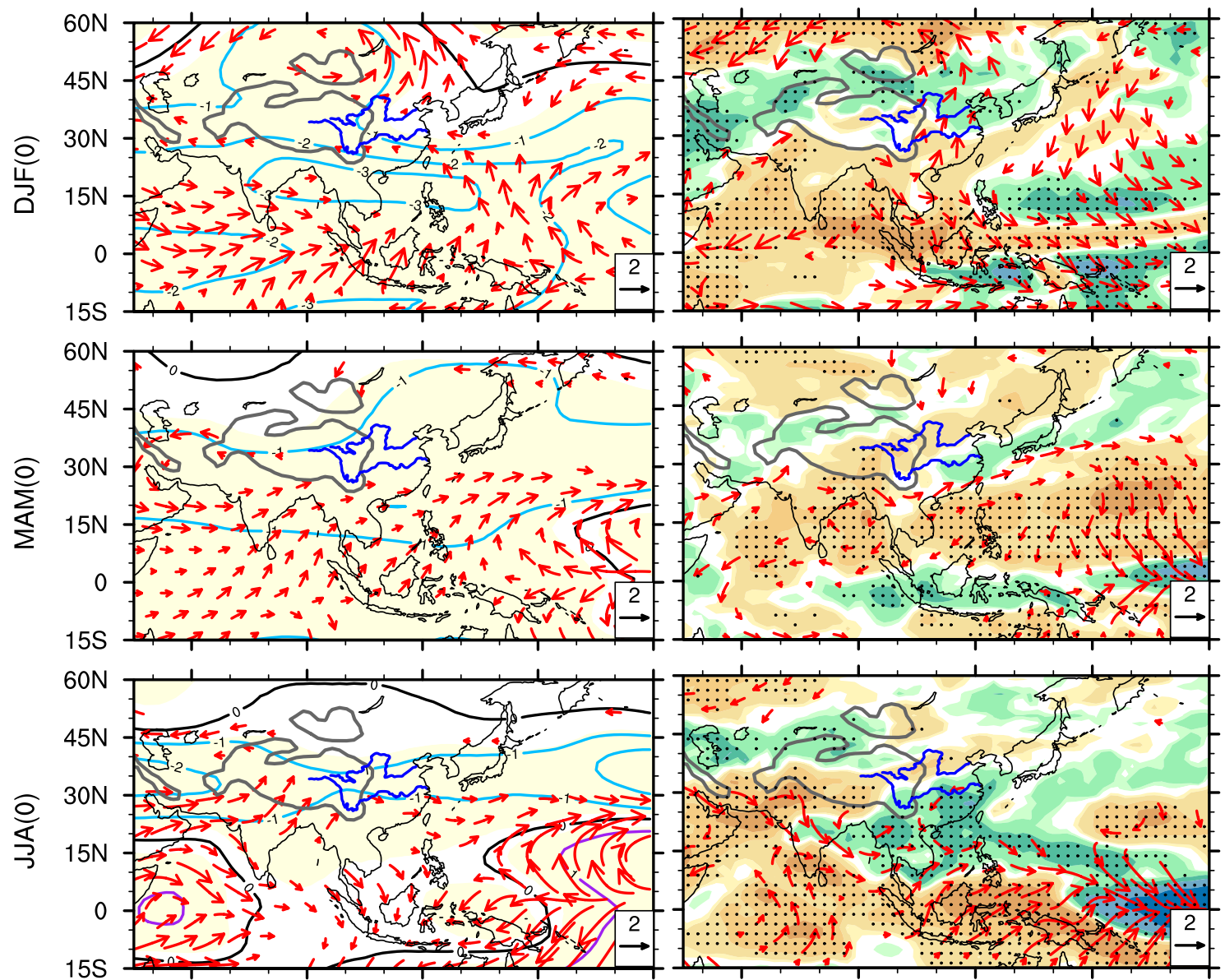

을
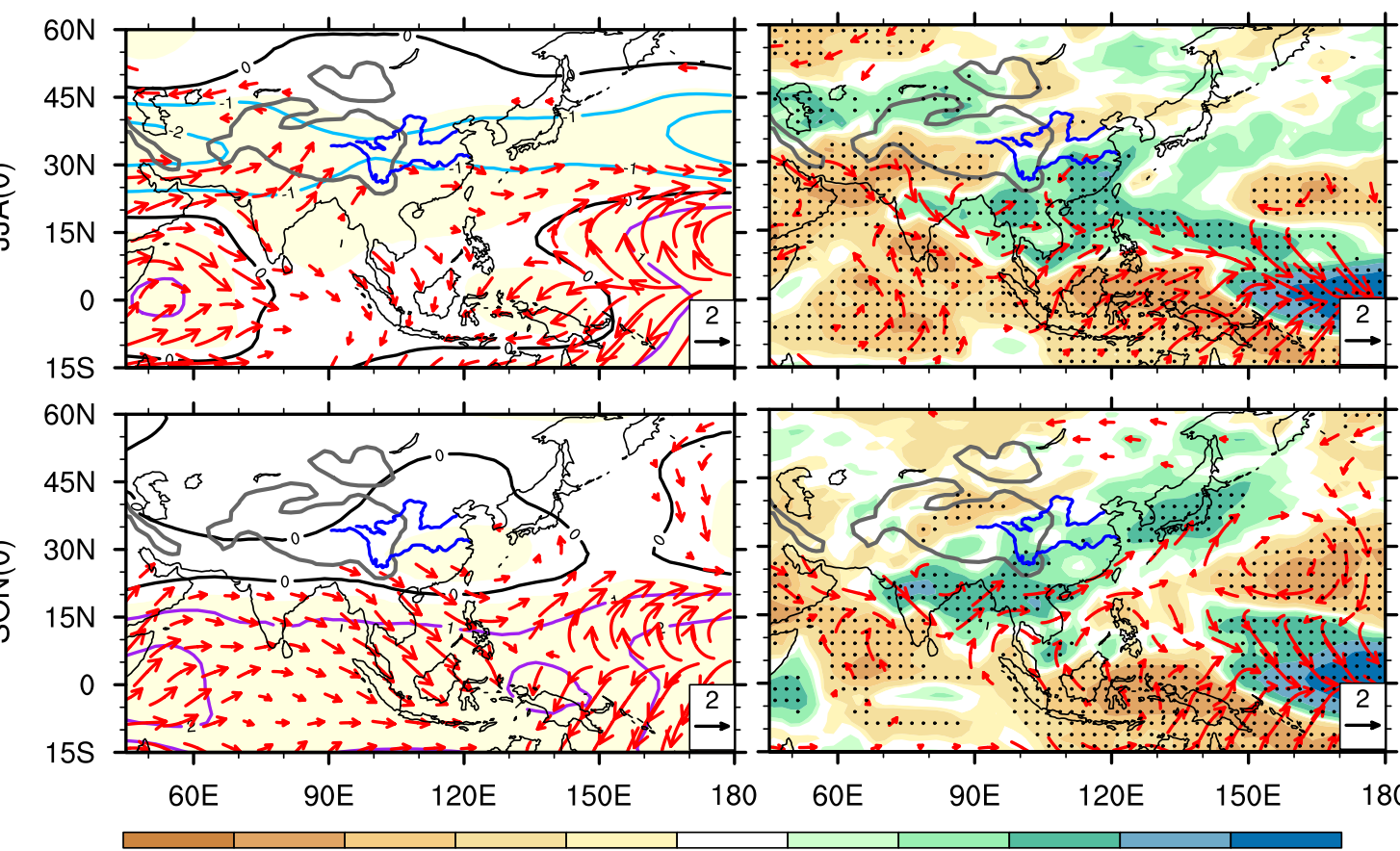

(b) $\operatorname{Pr} \&$ UV850

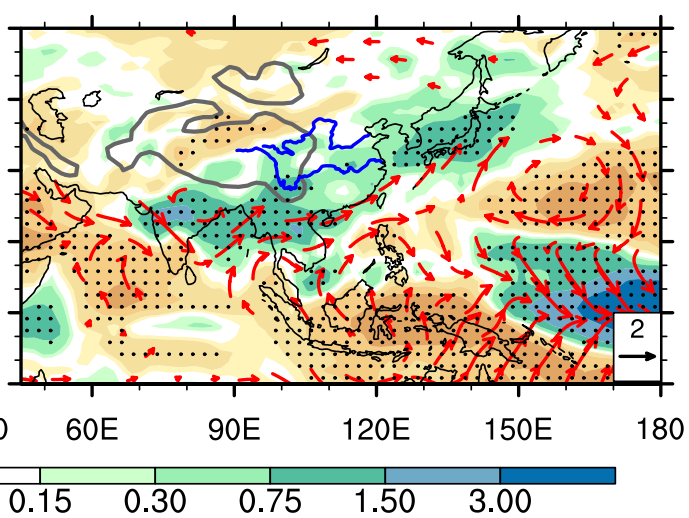

Fig. 11 Seasonal evolution in the developing stage of the responses to the global SSTA forcing, with ideal quadrennial POPs, in the FAMIL sensitivity experiment, in which results originate from a 20-cycle mean of the normalized differences between the positive and negative phases: a 200-hPa geopotential height [contours, with an interval of 1.0 (black contours are zero; purple contours are posi-

rapidly, resulting from the combined impacts of remote $\mathrm{El}$ Niño forcing, extratropical-tropical interaction, and local air-sea interaction in intraseasonal oscillation processes (Wang and Zhang 2002). The descending motion forced remotely by the central Pacific warming, and the in situ tive; blue contours are negative; yellow shading denotes the $95 \%$ confidence level)] and 200-hPa horizontal wind [vectors (red vectors denote the $95 \%$ confidence level)]; b precipitation [shading (black dots denote the $95 \%$ confidence level)] and 850 -hPa horizontal wind [vectors (red vectors denote the 95\% confidence level)]

cool SSTA, result in the suppressed convective heating, which induces a Rossby wave response associated with the anomalous anticyclone (Wang et al. 2000). It starts to develop over the South China Sea in SON(0), peaks over the Philippine Sea in $\operatorname{DJF}(1)$, and extends to the western 
(a) H200 \& UV200
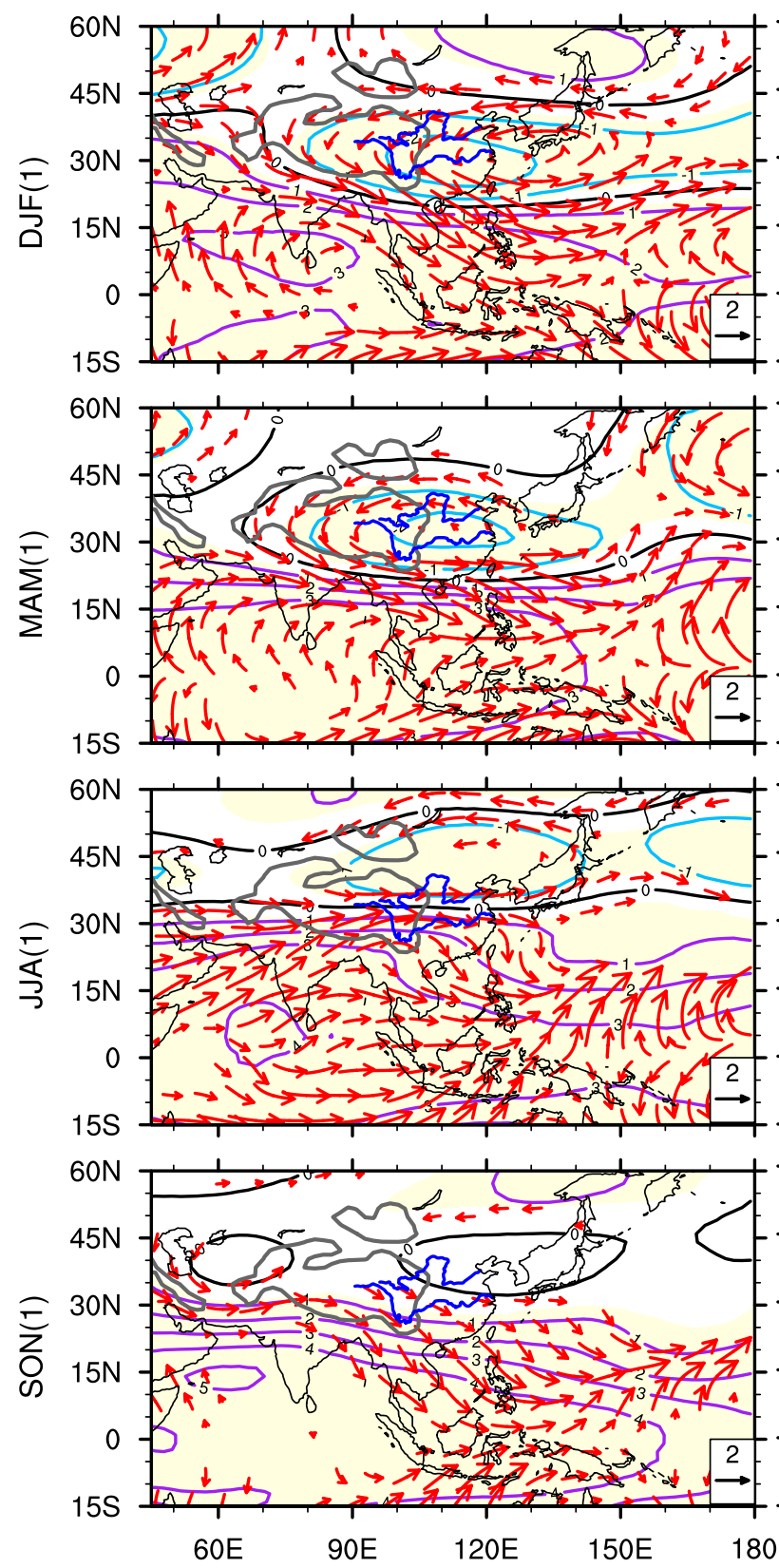

(b) $\operatorname{Pr} \&$ UV850
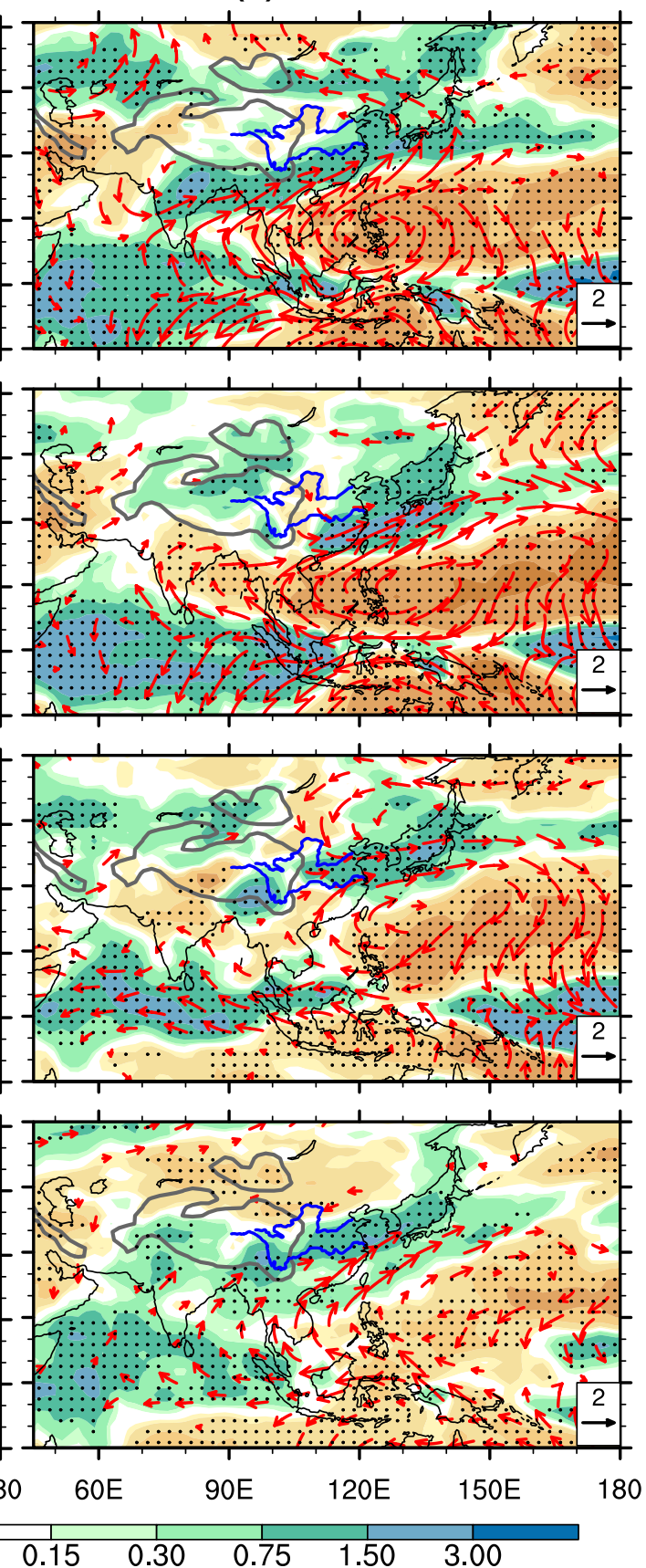

Fig. 12 As in Fig. 11 but for the decaying stage

North Pacific and North Indian Ocean, persisting from MAM(1) to SON(1) throughout the decaying stage. These features are in accordance with the ENSO-related results obtained by Wu et al. (2003). In MAM(1), the in situ windevaporation-SST feedback mechanism over the western North Pacific favors its maintenance (Wang et al. 2000, 2003). A tropical Indian Ocean warming with a one-season lag behind the El Niño results from the surface heat flux adjustments without ocean dynamics, because the tropical circulation induced by ENSO reduces the cloud cover and evaporation (Klein et al. 1999; Alexander et al. 2002; Lau and Nath 2003; Tokinaga and Tanimoto 2004). In JJA(1) and SON(1), the anomalous easterly flow on the south flank of the westward-extended anomalous anticyclone over the Indian Ocean-western North Pacific weakens the prevailing southwest monsoon. The reduction in surface evaporation results in continuous warming in the North Indian Ocean (Du et al. 2009). Meanwhile, the atmospheric convective 
heating induces the anomalous easterly flow over the Maritime Continent and enhances the anomalous anticyclone over the western North Pacific via the eastward-propagating warm Kelvin wave and Ekman divergence (Xie et al. 2009). This cross-basin coupled mode and its air-sea interaction mechanism support the concurrence of the anomalous western North Pacific anticyclone and the warming of the IOBM (Kosaka et al. 2013).

In the upper troposphere over East Asia, a significant anomalous cyclone with an equivalent barotropic vertical structure develops over Northeast Asia in $\operatorname{MAM}(0)$, then shifts southwestwards to the Tibetan Plateau from JJA(0) to MAM(1) before retreating northeastwards from JJA(1) to SON(1). Previous studies have documented that its southwestwards motion in the developing stage of ENSO deepens the East Asian trough, which triggers a cold-air outbreak and energizes the anomalous Philippine Sea anticyclone in SON(0). This is attributable to the Rossby wave response to anomalous heating over the tropical central Pacific and the surface cooling in Northeast Asia, and is linked with the anomalous heating induced by ENSO over the western North Pacific and South Asia (Wang and Zhang 2002; Wu et al. 2003). Its evolution alongside a low-level anomalous cyclone beneath, has a considerable impact on precipitation anomalies in East Asia. In $\operatorname{MAM}(0)$, the anomalous cyclone appears in the lower troposphere in Northeast Asia. Climatologically, the convergence of the southwesterly over southern China and the northwesterly over northern China enhances the rainfall over southern China. In JJA(0), the negative anomaly of the Tibetan Plateau heating can induce an anomalous low-level anticyclone over Northeast Asia via a stationary barotropic Rossby wave (Wang et al. 2008a, 2014; Hu and Duan 2015). This explains why the anomalous low-level cyclone over Northeast Asia weakens obviously in comparison with that in $\operatorname{MAM}(0)$. Following the upper-level anomalous cyclone, the low-level anomalous cyclone develops over the basin of the Yangtze River and Yellow River in SON(0), resulting in suppressed rainfall over northern China and enhanced rainfall over southern China. This shifts northwards from $\operatorname{DJF}(1)$ to MAM(1), and the southeasterly to its eastern flank leads to a more northward transportation of water vapor, which induces the positive anomalies of precipitation over most parts of East Asia. The anomalous cyclone peaks in northern China in JJA(1). Attributable to the mechanical isolation of the Mongolia Plateau and the Tibetan Plateau, the northwesterly flow enhances to their east. This induces convergence of the warm and moist flow from the south and the cold and dry flow from the north, and enhances the main rainfall band of the East Asian summer monsoon from the Yangtze River to Japan.

The comparison reveals a distinct difference in the anomalous response of circulation and precipitation in summer between the developing and decaying stages. The patterns of low-level circulation and precipitation remain similar from MAM(1) to SON(1). However, the low-level anomalous cyclone over Northeast Asia disappears in $\mathrm{JJA}(0)$, in comparison to that in $\operatorname{MAM}(0)$, and reappears in $\operatorname{SON}(0)$. Meanwhile, the anomalous Philippine Sea cyclone replaces the anomalous anticyclone in $\operatorname{MAM}(0)$ and $\operatorname{SON}(0)$. But why do the patterns of evolution break off in summer of the developing stage? As explained in the following, the different external remote forcing state can account for these different responses in summer in the developing and decaying stages. The El Niño is developing and decaying in two separate stages. In JJA(0) and JJA(1), the anomalies of atmospheric heating over the Indian Ocean are opposite. In $\operatorname{JJA}(0)$, the negative anomalous heating over the integral Tibetan Plateau facilitates an anomalous anticyclone over Northeast Asia and an anomalous cyclone over the Philippine Sea. In JJA(1), the precipitation anomaly in the Tibetan Plateau shows a positive-negative-positive pattern from west to east. The anomalous patterns of circulation and precipitation in East Asia are quite similar to the response to the heat forcing over the central and eastern Tibetan Plateau derived from the results of $\mathrm{Hu}$ and Duan (2015). Therefore, our understanding of the responses in a quasi-quadrennial cycle should take account of the combined effects of the large-scale heating induced by the global SSTA, the regional-scale oceanic forcing, the crossbasin interaction of oceans, and the land heating feedback in a framework of ocean-land-atmosphere interaction.

\section{Summary}

\subsection{Conclusions}

The present study reveals that the leading mode of the global SSTA in terms of interannual variability is a quasiquadrennial oscillation pattern. During the evolution of such a quasi-quadrennial cycle, an El Niño event develops in the tropical central and eastern Pacific and a cold IOBM changes to an IOD in the tropical Indian Ocean in the developing stage, while the El Niño event decays gradually and a warm IOBM appears in the decaying stage. Based on multi-source observational data from 1979 to 2013, the relationships between the global SSTA quasi-quadrennial POPs and the evolutions of circulation and precipitation in East Asia in terms of interannual variability are investigated through ACP analysis, which explores the different responses in the developing and decaying stages. Results from a numerical simulation in an AGCM verify the robustness of the circulation and precipitation responses in East Asia. 
Coupled with the variation of the global SSTA in a quasi-quadrennial cycle, the evolutions of circulation and precipitation anomalies in East Asia vary remarkably in different seasons. From winter to autumn in the developing year, southern China gets wetter, but the situation is opposite in the north. In the decaying year, the precipitation over most regions of East Asia is above normal from winter to spring, and the main rainfall band from the Yangtze River to South Japan is enhanced in summer. Corresponding to the precipitation anomalies, an anomalous Philippine Sea anticyclone occurs in winter and spring, but is replaced by an anomalous cyclone in summer, before reappearing and persisting from autumn to the decaying year. Moreover, an upper-level anomalous cyclone gradually moves from Northeast Asia to the Tibetan Plateau from spring in the developing year to spring in the decaying year, and then retreats back to Northeast Asia from summer to autumn in the decaying year. In the lower troposphere, an anomalous cyclone occurs over Northeast Asia in spring, which leads to a cold-air to the south and converges with the anomalous southwesterly flow induced by the anomalous Philippine Sea anticyclone, resulting in the enhancement of rainfall in spring over southern China. However, it weakens in summer, and strengthens again from autumn to the following summer. In the decaying year, the anomalous low-level East Asian cyclone contributes greatly to the enhanced precipitation over northern China in winter and spring, as well as the enhancement of the Yangtze River-South Japan main rainfall band in summer. The anomalous cyclone in East Asia, with an equivalent barotropic structure, couples with the Philippine Sea anticyclone. In comparison to the crucial effects of the anomalous Philippine Sea anticyclone documented in previous studies, this study emphasizes the important role of the anomalous cyclone at mid-latitudes, especially from winter to summer in the decaying year. Both play an important role in the precipitation anomaly responses over East Asia to the global SSTA quasi-quadrennial POPs, via processes of tropics-subtropics-mid-latitudes interaction.

The circulation patterns in summer of the developing year are distinct from the continuous change in circulation patterns in the decaying year. In the developing year, the anomalous low-level cyclone over Northeast Asia in summer is weaker than that in spring, and the anomalous Philippine Sea cyclone in summer replaces the anomalous anticyclone in spring. Subsequently, both the anomalous Northeast Asia cyclone and the anomalous Philippine Sea anticyclone reappear and develop in autumn. The abrupt change in circulation patterns in summer of the developing year is possibly related to the anomalous weakening of the Tibetan Plateau heating, which can induce an anomalous equivalent barotropic anticyclone over Northeast Asia via a quasi-stationary Rossby wave, and facilitate the anomalous
Philippine Sea cyclone via a Rossby wave along the South Asian monsoon westerly.

As the response to the global SSTA quasi-quadrennial POPs, the anomalous cyclone in the mid-latitudes of East Asia can be attributed to global large-scale heating and Tibetan Plateau thermal feedback. The remote forcing of the Indian Ocean-Pacific and the local air-sea interaction together modulate the anomalous Philippine Sea anticyclone/cyclone. The different SSTA modes in the Indian Ocean and the developing/decaying phase of El Niño events in the Pacific contribute to the asymmetrical response in the developing and decaying stages. Therefore, these anomalies can be attributed to the combined effects of global large-scale heating, regional oceanic forcing, and the thermal feedback of the land.

\subsection{Discussion}

We suggest in the present study that the feedback of the Tibetan Plateau heating from the global SSTA forcing in summer plays a crucial role in modulating the circulation and precipitation over East Asia. In quantitative terms, the contributions of the Tibetan Plateau thermal forcing in the developing and decaying stages need further investigation. On the other hand, how the global SSTA impacts upon the Tibetan Plateau heating and the relevant mechanisms involved still remain unclear. To a certain degree, the global quadrennial SSTA POPs derived from observations are the result of air-sea interaction, and hence further experiments based on an air-sea coupled model are desirable to further clarify the contribution of air-sea feedback.

Previous studies have suggested that interdecadal changes can affect the relationship between ENSO and the interannual variability of the EAM in certain seasons and regions, especially before and after the late 1970s (Wu and Wang 2002; Wu and Mao 2016). Since the observational data used here span from 1979 to 2013, the global quadrennial SSTA POPs and their impacts on the interannual variability of the EAM revealed in this study can only reflect their relationships after the late 1970s. Therefore, the combined effect of interdecadal changes and the interannual variability of the global SSTA on East Asian climate is also a planned avenue of future work for our group.

Acknowledgements This work was jointly supported by the National Natural Science Foundation of China (91337216, 91637312), the Chinese Academy of Sciences Projects (XDA11010402, QYZDY-SSW-DQC018), the Third Tibetan Plateau Scientific Experiment: Observations for Boundary Layer and Troposphere (GYHY201406001), and the Special Program for Applied Research on Super Computation of the NSFC-Guangdong Joint Fund (the second phase).

Open Access This article is distributed under the terms of the Creative Commons Attribution 4.0 International License (http:// 
creativecommons.org/licenses/by/4.0/), which permits unrestricted use, distribution, and reproduction in any medium, provided you give appropriate credit to the original author(s) and the source, provide a link to the Creative Commons license, and indicate if changes were made.

\section{References}

Adler RF, Huffman GJ, Chang A et al (2003) The version-2 global precipitation climatology project (GPCP) monthly precipitation analysis (1979-present). J Hydrometeorol 4:1147-1167. doi:10.1175/1525-7541(2003)004<1147:TVGPCP>2.0.CO;2

Alexander MA, Bladé I, Newman M, Lanzante JR, Lau N-C, Scott JD (2002) The atmospheric bridge: the influence of ENSO teleconnections on air-sea interaction over the global oceans. J Clim 15:2205-2231. doi:10.1175/1520-0442(2002)015<2205:TABTI $\mathrm{O}>2.0 . \mathrm{CO} ; 2$

Alexander MA, Lau N-C, Scott JD (2004) Broadening the atmospheric bridge paradigm: ENSO teleconnections to the tropical West Pacific-Indian oceans over the seasonal cycle and to the North Pacific in summer. In: Wang C, Xie SP, Carlton JA (eds) Earth's Climate. American Geophysical Union, Washington, DC, pp 85-103. doi:10.1029/147GM05

Ashok K, Behera SK, Rao SA, Weng H, Yamagata T (2007) El Niño Modoki and its possible teleconnection. J Geophys Res 112:C11007. doi:10.1029/2006JC003798

Bejarano L, Jin F-F (2008) Coexistence of equatorial coupled modes of ENSO. J Clim 21:3051-3067. doi:10.1175/2007jcli1679.1

Chang C-P, Zhang Y, Li T (2000) Interannual and interdecadal variations of the East Asian summer monsoon and tropical Pacific SSTs. Part I: roles of the subtropical ridge. J Clim 13:4310-4325. doi:10.1175/1520-0442(2000)013<4310:IAIVOT>2.0.CO;2

Chen L, Chen D, Shen R, Zhang Q (1990) The Interannual oscillation of rainfall over China and its relation to the interannual oscillation of the air-sea system. J Meteorol Res 4:598-612

Dee DP, Uppala SM, Simmons AJ et al (2011) The ERA-Interim reanalysis: configuration and performance of the data assimilation system. Q J R Meteorol Soc 137:553-597. doi:10.1002/qj.828

Ding Y, Chan JCL (2005) The East Asian summer monsoon: an overview. Meteorol Atmos Phys 89:117-142. doi:10.1007/ s00703-005-0125-Z

Du Y, Xie S-P, Huang G, Hu K (2009) Role of air-sea interaction in the long persistence of El Niño-induced North Indian Ocean warming. J Clim 22:2023-2038. doi:10.1175/2008JCLI2590.1

Duan A, Wu G (2005) Role of the Tibetan Plateau thermal forcing in the summer climate patterns over subtropical Asia. Clim Dyn 24:793-807. doi:10.1007/s00382-004-0488-8

Duan A, Wang M, Lei Y, Cui Y (2013) Trends in summer rainfall over China associated with the Tibetan Plateau sensible heat source during 1980-2008. J Clim 26:261-275. doi:10.1175/ JCLI-D-11-00669.1

Fraedrich K, Ziehmann C, Sielmann F (1995) Estimates of spatial degrees of freedom. J Clim 8:361-369. doi:10.1175/1520-0442(1995)008<0361:EOSDOF > 2.0.CO;2

Fu CB, Teng XL (1988) Summer climate anomalies of China in association with ENSO phenomenon. Sci Atmos Sin, special issue for 60th anniversary of IAP, pp 125-137

Gill AE (1980) Some simple solutions for heat-induced tropical circulation. Q J R Meteorol Soc 106:447-462. doi:10.1002/ qj. 49710644905

Guan Z, Yamagata T (2003) The unusual summer of 1994 in East Asia: IOD teleconnections. Geophys Res Lett 30:1544. doi:10.1 029/2002GL016831
Hasselmann K (1988) PIPs and POPs: the reduction of complex dynamical systems using principal interaction and oscillation patterns. J Geophys Res 93:11015-11021. doi:10.1029/ JD093iD09p11015

He C, Zhou T, Wu B (2015) The key oceanic regions responsible for the interannual variability of the western North Pacific subtropical high and associated mechanisms. J Meteorol Res 29:562575. doi:10.1007/s13351-015-5037-3

Hu J, Duan A (2015) Relative contributions of the Tibetan Plateau thermal forcing and the Indian Ocean sea surface temperature basin mode to the interannual variability of the East Asian summer monsoon. Clim Dyn 45:2697-2711. doi:10.1007/ s00382-015-2503-7

Huang R, Wu Y (1989) The influence of ENSO on the summer climate change in China and its mechanism. Adv Atmos Sci 6:2132. doi:10.1007/BF02656915

Jiang N, Neelin JD, Ghil M (1995) Quasi-quadrennial and quasi-biennial variability in the equatorial Pacific. Clim Dyn 12:101-112. doi:10.1007/bf00223723

Klein SA, Soden BS, Lau N-C (1999) Remote sea surface temperature variations during ENSO: evidence for a tropical atmospheric bridge. J Clim 12:917-932. doi:10.1175/1520-0442(1999)012<0917:RSSTVD>2.0.CO;2

Kosaka Y, Xie S-P, Lau N-C, Vecchi GA (2013) Origin of seasonal predictability for summer climate over the northwestern Pacific. Proc Natl Acad Sci 110:7574-7579. doi:10.1073/ pnas. 1215582110

Lau N-C, Nath MJ (2003) Atmosphere-ocean variations in the Indo-Pacific sector during ENSO episodes. J Clim 16:3-20. doi:10.1175/1520-0442(2003)016<0003:AOVITI >2.0.CO;2

Liu S, Duan A (2017) Impacts of the leading modes of the tropical Indian Ocean sea surface temperature anomaly on the subseasonal evolution of the circulation and rainfall over East Asia during boreal spring and summer. J Meteorol Res 31:171-186. doi:10.1007/s13351-016-6093-z

Liu Y, Wu G, Ren R (2004) Relationship between the subtropical anticyclone and diabatic heating. J Clim 17:682-698. doi:10.1175/1520-0442(2004)017<0682:RBTSAA > 2.0.CO;2

Lu R, Lu S (2014) Local and remote factors affecting the SST-precipitation relationship over the western North Pacific during summer. J Clim 27:5132-5147. doi:10.1175/JCLI-D-13-00510.1

Luo HB, Chen R (1995) The impact of the anomalous heat sources over the eastern Tibetan Plateau on the circulation over East Asia in summer half-year. Scientia Meteorol Sin 15:94-102 (in Chinese)

Matsuno T (1966) Quasi-geostrophic motions in the equatorial area. J Meteorol Soc Jpn 44:25-42

Penland C (1989) Random forcing and forecasting using principal oscillation pattern analysis. Mon Weather Rev 117:2165-2185. doi:10.1175/1520-0493(1989)117<2165:RFAFUP > 2.0.CO;2

Qu X, Huang G (2012) Impacts of tropical Indian Ocean SST on the meridional displacement of East Asian jet in boreal summer. Int J Climatol 32:2073-2080. doi:10.1002/joc.2378

Rasmusson EM, Carpenter TH (1982) Variations in tropical sea surface temperature and surface wind fields associated with the Southern Oscillation/El Niño. Mon Weather Rev 110:354-384. doi:10.1175/1520-0493(1982)110<0354:VITSST > 2.0.CO;2

Rayner NA, Parker DE, Horton EB, Folland CK, Alexander LV, Rowell DP, Kent EC, Kaplan A (2003) Global analyses of sea surface temperature, sea ice, and night marine air temperature since the late nineteenth century. J Geophys Res 108:4407. doi:10.1029/2 002JD002670

Ren R, Rao J, Wu G, Cai M (2016) Tracking the delayed response of the northern winter stratosphere to ENSO using multi reanalyses and model simulations. Clim Dyn. doi:10.1007/s00382-0163238-9(in press) 
Rong X, Zhang R, Li T (2010) Impacts of Atlantic sea surface temperature anomalies on Indo-East Asian summer monsoonENSO relationship. Chin Sci Bull 55:2458-2468. doi:10.1007/ s11434-010-3098-3

Saji NH, Goswami BN, Vinayachandran PN, Yamagata T (1999) A dipole mode in the tropical Indian Ocean. Nature 401:360-363. doi: $10.1038 / 43855$

Song F, Zhou T (2014a) Interannual variability of East Asian summer monsoon simulated by CMIP3 and CMIP5 AGCMs: Skill dependence on Indian Ocean-western Pacific anticyclone teleconnection. J Clim 27:1679-1697. doi:10.1175/ JCLI-D-13-00248.1

Song F, Zhou T (2014b) The climatology and interannual variability of East Asian summer monsoon in CMIP5 coupled models: does air-sea coupling improve the simulations? J Clim 27:8761-8777. doi:10.1175/JCLI-D-14-00396.1

Tang B (1995) Periods of linear development of the ENSO cycle and POP forecast experiments. J Clim 8:682-691. doi:10.1175/1520-0442(1995)008<0682:POL.>2.0.CO;2

Tao SY, Chen LX (1987) A review of recent research on the East Asian summer monsoon in China. In: Chang CP, Krishnamurti TN (eds) Monsoon Meteorology. Oxford University Press, Oxford, pp 60-92

Tokinaga H, Tanimoto Y (2004) Seasonal transition of SST anomalies in the tropical Indian Ocean during El Niño and Indian Ocean dipole years. J Meteorol Soc Jpn 82:1007-1018. doi:10.2151/ jmsj.2004.1007

Trenberth KE, Branstator GW, Karoly D, Kumar A, Lau N-C, Ropelewski C (1998) Progress during TOGA in understanding and modeling global teleconnections associated with tropical sea surface temperatures. J Geophys Res 103:14291-14324. doi:10.1029/97JC01444

von Storch H, Bürger G, Schnur R, von Storch JS (1995) Principal oscillation patterns: a review. J Clim 8:377-400. doi:10.1175/1520-0442(1995)008<0377:POPAR > 2.0.CO;2

Wang C (2001) A unified oscillator model for the El Niño-Southern Oscillation. J Clim 14:98-115. doi:10.1175/1520-0442(2001)014<0098:AUOMFT>2.0.CO;2

Wang L, Chen W (2014) An intensity index for the East Asian winter monsoon. J Clim 27:2361-2374. doi:10.1175/ JCLI-D-13-00086.1

Wang B, Zhang Q (2002) Pacific-east Asian teleconnection. Part II: how the Philippine Sea anomalous anticyclone is established during El Niño development. J Clim 15:3252-3265. doi:10.1175/1520-0442(2002)015<3252:PEATPI > 2.0.CO;2

Wang B, Wu R, Fu X (2000) Pacific-East Asian teleconnection: how does ENSO affect East Asian climate? J Clim 13:1517-1536. doi:10.1175/1520-0442(2000)013<1517:PEATHD > 2.0.CO;2

Wang B, Wu R, Li T (2003) Atmosphere-warm ocean interaction and its impacts on Asian-Australian monsoon variation. J Clim 16:1195-1211. doi:10.1175/1520-0442(2003)16<1195:AOIAII $>2.0 . \mathrm{CO} ; 2$

Wang B, Bao Q, Hoskins B, Wu G, Liu Y (2008a) Tibetan Plateau warming and precipitation changes in East Asia. Geophys Res Lett 35:63-72. doi:10.1029/2008GL034330

Wang B, Wu Z, Li J, Liu J, Chang C-P, Ding Y, Wu G (2008b) How to measure the strength of the East Asian summer monsoon. J Clim 21:4449-4463. doi:10.1175/2008JCLI2183.1

Wang Z, Duan A, Wu G (2014) Time-lagged impact of spring sensible heat over the Tibetan Plateau on the summer rainfall anomaly in East China: case studies using the WRF model. Clim Dyn 40:1-14. doi:10.1007/s00382-013-1800-2

Wu R, Kirtman BP (2007) Observed relationship of spring and summer East Asian rainfall with winter and spring Eurasian snow. J Clim 20:1285-1304. doi:10.1175/JCLI4068.1
Wu X, Mao J (2016) Interdecadal modulation of ENSO-related spring rainfall over South China by the Pacific Decadal Oscillation. Clim Dyn 47:3203-3220. doi:10.1007/s00382-016-3021-y

Wu T-W, Qian Z-A (2003) The relation between the Tibetan winter snow and the Asian summer monsoon and rainfall: an observational investigation. J Clim 16:2038-2051. doi:10.1175/1520-0442(2003)016<2038:TRBTTW >2.0.CO;2

Wu R, Wang B (2002) A contrast of the East Asian summer monsoon-ENSO relationship between 1962-77 and 1978-93. J Clim 15:3266-3279. doi:10.1175/1520-0442(2002)015<3266:ACOT $\mathrm{EA}>2.0 . \mathrm{CO} ; 2$

Wu GX, Liu P, Liu YM et al (2000) Impacts of the sea surface temperature anomaly in the Indian Ocean on the subtropical anticyclone over the western Pacific - two-stage thermal adaptation in the atmosphere. Acta Meteorol Sin 58:513-522 (in Chinese)

Wu R, Hu Z-Z, Kirtman BP (2003) Evolution of ENSO-related rainfall anomalies in East Asia. J Clim 16:3742-3758. doi:10.1175/1520-0442(2003)016<3742:EOERAI > 2.0.CO;2

Wu G, Liu Y, He B, Bao Q, Duan A, Jin F-F (2012) Thermal controls on the Asian summer monsoon. Sci Rep 2:404. doi:10.1038/ srep00404

Xiao Z, Duan A (2016) Impacts of Tibetan Plateau snow cover on the interannual variability of the East Asian summer monsoon. J Clim 29:8495-8514. doi:10.1175/JCLI-D-16-0029.1

Xie S-P, Hu K, Hafner J et al (2009) Indian Ocean capacitor effect on Indo-western Pacific climate during the summer following El Niño. J Clim 22:730-747. doi:10.1175/2008JCLI2544.1

Xie S-P, Kosaka Y, Du Y, Hu K, Chowdary JS, Huang G (2016) Indowestern Pacific ocean capacitor and coherent climate anomalies in post-ENSO summer: a review. Adv Atmos Sci 33:411-432. doi:10.1007/s00376-015-5192-6

Yang S (1996) ENSO-snow-monsoon associations and seasonalinterannual predictions. Int J Climatol 16:125-134. doi:10.1002/ (SICI) 1097-0088(199602)16:2<125::AID-JOC999>3.0.CO;2-V

Yang J, Liu Q, Xie S-P, Liu Z, Wu L (2007) Impact of the Indian Ocean SST basin mode on the Asian summer monsoon. Geophys Res Lett 34:L02708. doi:10.1029/2006GL028571

Yang J, Liu Q, Liu Z (2010) Linking observations of the Asian monsoon to the Indian Ocean SST: possible roles of Indian Ocean basin mode and dipole mode. J Clim 23:5889-5902. doi:10.117 5/2010JCLI2962.1

Yu H-Y, Bao Q, Zhou L-J, Wang X-C, Liu Y-M (2014) Sensitivity of precipitation in aqua-planet experiments with an AGCM. Atmos Ocean Sci Lett 7:1-6. doi:10.3878/j.issn.1674-2834.13.0033

Yuan Y, Yang S (2012) Impacts of different types of El Niño on the East Asian climate: focus on ENSO cycles. J Clim 25:77027722. doi:10.1175/JCLI-D-11-00576.1

Yuan Y, Yang H, Zhou W, Li C (2008) Influences of the Indian Ocean dipole on the Asian summer monsoon in the following year. Int $\mathrm{J}$ Climatol 28:1849-1859. doi:10.1002/joc.1678

Zeng QC, Zhang BL, Liang YL, Zhao SX (1994) The Asian summer monsoon-A case study. Proc Indian Natl Sci Acad 60A:81-96

Zhou L-J, Liu Y-M, Bao Q, Yu H-Y, Wu G-X (2012) Computational performance of the high-resolution atmospheric model FAMIL. Atmos Ocean Sci Lett 5:355-359. doi:10.1080/16742834.2012. 11447024

Zhou L, Bao Q, Liu Y, Wu G, Wang W-C, Wang X, He B, Yu H, Li J (2015) Global energy and water balance: characteristics from Finite-volume Atmospheric Model of the IAP/LASG (FAMIL1). J Adv Model Earth Syst 7:1-20. doi:10.1002/2014MS000349

Zhu YF, Chen LX (2000) Study on the quasi-4-year oscillation of air/ sea interaction. Acta Meteorol Sin 14:293-306

Zhu YF, Chen LX, Yu RC (2004) Analysis of the relationship between the China anomalous climate variation and ENSO cycle on the quasi-four-year scale. J Trop Meteorol 10:1-13 